\title{
Information Globalization, Risk Sharing, and International Trade
}

\author{
Isaac Baley*, Laura Veldkamp Michael Waugh $^{\ddagger}$
}

June 23, 2014

\begin{abstract}
This paper studies the effect of reductions in information asymmetry - information globalization - on international risk sharing and trade flows. Information frictions are often invoked to explain low levels of international trade beyond those that measured trade frictions (tariffs, transportation costs, etc.) can explain. Using a relatively standard two-country general equilibrium model with asymmetric information about aggregate productivity, we find that more precise information about foreign productivity shocks reduces trade and international risk sharing. In other words, information frictions behave in the exact opposite manner as a standard trade cost.
\end{abstract}

Information frictions are often invoked to explain why cross-border trade is low, when measured trade frictions are small (see e.g., Obstfeld and Rogoff (2000), Portes and Rey (2005), or Anderson and van Wincoop (2004)). Intuitively, this sounds right - the uncertain state of foreign markets must deter many would-be exporters. This paper formally studies the effect reductions in imperfect information about the state of a foreign market - information globalization - have on international trade. We show that more precise information leads to less risk sharing and less international trade. Contrary to prevailing wisdom, information frictions behave in the exact opposite manner as an iceberg trade costs.

To explore the effects of information frictions on trade, we build a two-country, two-good endowment economy. The only twist on the standard environment is that agents can't perfectly predict what the international relative price will be when they choose how much to export. The information friction is that while the home market is perfectly predictable, exporting is an activity that offers a risky return. While there are many possible reasons why exporting may ential additional risk, we model a simple one: We assume that firms in each country know their home endowment, but are uncertain about the foreign endowment. Agents observe noisy signals about the foreign endowment, update with Bayes Law and then choose how much of

\footnotetext{
*Department of Economics, New York University, 19 W. 4th Street, New York, NY 10012; isaac.baley@nyu.edu; https://sites.google.com/a/nyu.edu/isaacbaley/.

${ }^{\dagger}$ Department of Economics, Stern School of Business, New York University, NBER and CEPR, 44 W. 4th Street, New York, NY 10012; lveldkam@stern.nyu.edu; http://www.stern.nyu.edu/ lveldkam.

${ }^{\ddagger}$ Department of Economics Stern School of Business, New York University, 44 W. 4th Street, New York, NY 10012; mwaugh@stern.nyu.edu; https://files.nyu.edu/mw134/public/index.html. We thank Callum Jones for outstanding research assistance.
} 
their endowment to export. Exports go to an international market where the price clears the market. From an exporter's perspective, the source of the uncertainty is irrelevant. The key issue is that the relative price of home goods and foreign goods is uncertain and, hence, the return to exporting is risky. To analyze the effect of smaller or larger information frictions, we study how varying the precision of the signal about the foreign endowment affects three objects of interest: trade volume, international risk sharing and expected utility.

Our main finding is that information globalization (more precise signals about foreign endowments) results in a smaller fraction of goods traded, on average. The mechanism at the heart of this finding is that more precise information prevents relative prices from fluctuating in a way that shares risk. To understand this mechanism, consider the following analogy: Suppose that there are two people. Each holds a lottery ticket. As long as neither knows the outcome of the lottery, they can each sell a claim to half the ticket and share risk. But as soon as a piece of information arrives that reveals the outcome of the lottery, the only possible price for that claim is half the realized value of the ticket. That post-information sale just exchanges money for money. It does not share risk. Information globalization is like revealing the outcome of the lottery. In good times, the other country exports more and you get more for your exports (like a large payment for half the winning ticket). In bad times, you get less (the payment for a losing ticket).

To explain the mechanics of how this plays out in a two-country equilibrium model and why it causes the trade share to fall, we first need to explore how information increases trade coordination. Countries' expected utility is higher with greater information precision because both achieve more balanced consumption bundles by coordinating their exports. When each country knows more about the other's productivity, they can anticipate better when the other country will export a lot. If the foreign country exports a lot, the relative price of the foreign goods must be low to clear the international market. That means that the relative price of home goods is high. High returns to exporting make the home country want to export more in these times when foreign exports are also high. Thus, changes in terms of trade create a motive for countries to coordinate their exports. If exports are coordinated, then times when the home good is abundant, home investors will also get to consume lots of foreign goods. When home goods are scarce, foreign exports will be lower and consumption of both goods at home will be low. This balance in consumption bundles makes trade volumes and utility more volatile, but also achieves higher average utility.

Information globalization and the resulting trade coordination also make the terms-of-trade a less effective hedge against productivity risk. As noted by Cole and Obstfeld (1991), equilibrium movements in the terms of trade are a good hedge for a country's production risk. When a country's productivity is high, the country will export lots, but the benefits of high productivity will be partially offset by the fact that the price of 
those exports will be low. Conversely, when productivity is low and exports are low, the high relative price of the scarce export good will help to increase utility. But what if the foreign country is informed about home productivity? If foreign firms anticipate that home productivity is high, they expect a higher relative price for their goods and export more. By exporting more, the foreign country mitigates the decline in the home good's price, which encourages the home country to export even more and further increases home utility. Conversely, when foreign firms anticipate low home exports, they expect a low price for foreign goods and thus export less, which offsets some of the rise in the relative price of home goods. Because better information allows each country to better anticipate the other's exports, it makes the relative price less sensitive to each country's productivity. In short, information globalization makes relative prices less flexible and thus reduces the ability of international prices to share risk.

Finally, we come back to the reason why information globalization reduces average trade volume. The decline in trade arises because of how information change second-order beliefs. Second-order beliefs are one country's beliefs about what the other country believes. With information globalization, the home country knows that foreigners will anticipate when their productivity is low and knows that foreigners will reduce their exports and thus reduce the relative price of home goods in these low-productivity states. Anticipating that more precise information will lower their relative price when productivity is low, home firms export less. Of course, the reverse logic dictates that in high-productivity states, information globalization should lead home firms to export more. However, since the effect on trade share is the effect on trade, divided by total output, the effects when productivity and output are low are magnified. Thus, the second-order belief effect is that when then other country knows more about your state, and you know that they know this, you anticipate that the price of your good will be less in low productivity state and therefore export less. This effect causes a large decline in trade shares in low-productivity states and a small increase in the trade share in high-productivity states, which on average lowers the fraction of goods exported.

Section 1 sets up our two-country, two-good endowment economy with asymmetric information. Agents value the consumption of a composite good that aggregates the consumption of the two goods with a constant elasticity of substitution. Each country has an aggregate endowment of one of the goods and must trade to obtain some of the other good. The size of a country's aggregate endowment is known to residents of the country, but not to foreigners. Agents have prior beliefs about the aggregate endowment in the other country, observe a noisy signal about the endowment, and update with Bayes' Law. Because they don't know how much the other country has produced, they are uncertain about the terms of trade for their export good. That causes export goods to have an uncertain return. Agents form beliefs about the terms of trade and then choose a quantity of their good to export. All goods arrive in an international market. The price clears 
that market. Then each country gets some of the other country's goods in return for their exports. Finally, all agents consume.

This is a standard bilateral trade model where the novel piece is the lack of knowledge that each country has about the other's productivity and the noisy signal that one country observes about the other's productivity. By changing the variance of the signal noise, we can gauge the effect of aggregate information frictions on trade.

Section 2 describes how we choose parameter values for the model and the numerical simulation techniques that we use to compute the effect of the information friction on trade, consumption and prices. Section 3 shows results for three economies. In the first economy, called "no information" agents have prior beliefs about the productivity in the other country and receive no additional information about that productivity level before they choose how much to export. In the second economy, called "noisy signals," agents get a signal that conveys some information about what the other country's aggregate productivity will be. This signal allows them to choose exports that covary with foreign exports. In the third economy, called "full information," each country knows exactly what the aggregate productivity in the other country will be.

The results show that exports rise by 7\% of GDP when the economy moves from full information to noisy signals. They rise by $9 \%$ of GDP when the economy moves from full information to no information. Thus information globalization represents a moderate trade friction. We then decompose the first-order condition into a term that depends on second-order beliefs and a residual covariance term. We show numerically that changes in information precision have little effect on the covariance term, but large effects on the secondorder belief term. Finally, we shut off the second-order belief effect by solving a model where only the home country gets an increase in signal precision. In this setting, with our main mechanism switched off, an increase in signal precision has almost no effect on the average trade share.

To contrast the effect of information frictions and iceberg trade costs, we introduce a proportional cost to trade in our full-information model and vary the size of that cost. We see that as trade costs increase, trade falls, as expected. With respect to consumption, information frictions and trade costs have more similar effects. Both increase expected consumption of the composite good. However, information has nonmonotonic effects on the average quantity of each of the two goods consumed, whereas trade frictions do not. Finally, information frictions reduce the variance of consumption and increase the variance of relative prices. This also contrasts with the case of trade costs where a larger trade cost increases the variance of consumption and has a non-monotonic effect on the variance of the relative price.

What we take away from this investigation is not that information globalization is our preferred explanation any particular puzzle or observed phenomenon in trade. To the contrary, we argue that to explain low 
observed levels of trade, we may need to look to other frictions, besides imperfect information about foreign aggregate conditions. The conclusion from these results is that information frictions that take the form of imperfect knowledge about the aggregate economic conditions in other countries have an effect that is not at all like the effect of a proportional cost to international trade.

Related papers There is a spate of recent papers modeling and measuring information frictions in trade. The most closely related is Steinwender (2014), who models exporters in one country who learn about exogenous market prices in another country. The information they learn decreases uncertainty and increases the expected profits from trade, increasing trade volume and improving welfare. Our paper is similar because agents learn about aggregate economic conditions in the other country. But it comes to opposite conclusions because we increase the precision of both countries' information and endogenize the international price.

A series of other papers look at a fundamentally different type of information friction, one that is more similar to a search friction. In Allen (2013), Petropoulou (2011), Rauch and Watson (2004) and Eaton, Eslava, Krizan, Kugler, and Tybout (2011), information plays a central role, but unlike this paper, there is no uncertainty about aggregate economic conditions. Instead, producers are uncertain about firm- or matchspecific variables such as the location of the best trading partner, the quality of their match or local demand for their specific product. While all these are undoubtedly important information frictions, good-specific uncertainty is just as relevant for starting a firm at home as it is for exporting abroad. For these frictions to explain why a new firm typically prefers to learn about their firm-specific variables at home, rather than abroad, there must be something unknown at the country level that interacts with these frictions. As such, our model complements these theories by filling in that missing piece, the role of uncertainty about a foreign country's state.

The effect of information globalization on risk sharing is similar to the effect of allowing international borrowing (Brunnermeier and Sannikov, 2014). Both mechanisms undermine risk-sharing, but ours has the opposite predictions for trade volumes.

In financial markets, information also frequently inhibits risk-sharing. The Hirshleifer (1971) effect arises when information precludes trade in assets whose payoffs are contingent on an outcome revealed by the information. Our effect is distinct because 1) our signals are private to each country, not public and 2) it works through an effect of the quantity exported on the international relative price. Our effect does not change the set of securities traded because no financial securities are traded in this model. 


\section{Benchmark Model}

In order to understand how an information friction and an iceberg cost differ, we write down a simple model with two countries, an endowment economy, an iceberg cost and an information asymmetry. The first three ingredients constitute a standard equilibrium model of trade. The information asymmetry is that agents in each country know their own country's aggregate endowment, but have imperfect information about the other country's endowment. The key feature of the model is that the relative price of goods is not known at the time when exports are chosen. It could be that there is shipping delay. This could be a demand shock. It could be that some fixed costs must be incurred to export before export contracts are written. But what this captures is the idea that exporting is risky. It is the essence of an information asymmetry: Something is known when one sells domestically that is unknown when selling abroad. Our question is what happens when the unknowns in exporting become more known.

This is a repeated static model with the following economic environment.

Preferences: There are 2 countries and a continuum of agents within each country. We denote individual variables with lower case and aggregates with upper case. The problems are symmetric across countries, so we only describe the problem for the domestic country. Agents like to consume two goods, $x$ and $y$ and their utility flow each period is $\mathbb{E}[c]$, where the consumption composite good is $c=\left(c_{x}^{\theta}+c_{y}^{\theta}\right)^{1 / \theta}, \theta \in(0,1)$. The elasticity of substitution across goods is $\nu=\frac{1}{1-\theta}$.

Endowments: Each agent in the domestic country has an idiosyncratic endowment of $z_{x}$ units of good $x$, where $\ln z_{x} \sim \mathcal{N}\left(\mu_{x}, \sigma_{x}^{2}\right)$. Each agent in the foreign country has an idiosyncratic endowment $z_{y}$ units of good $y$, where $\ln z_{y} \sim \mathcal{N}\left(\mu_{y}, \sigma_{y}^{2}\right)$. The means of these distributions are themselves independent random variables: $\mu_{x} \sim \mathcal{N}\left(m_{x}, s_{x}^{2}\right)$ and $\mu_{y} \sim \mathcal{N}\left(m_{y}, s_{y}^{2}\right)$. Because they are average endowment around which all individual endowments are distributed, $\mu_{x}$ and $\mu_{y}$ are aggregate shocks. If we let $\Phi$ denote the cumulative density (cdf) of a standard normal variable, then the conditional cdf's of $z_{x}$ and $z_{y}$ are $F\left(\ln \left(z_{x}\right) \mid \mu_{x}\right)=\Phi\left(\left(\ln \left(z_{x}\right)-\mu_{x}\right) / \sigma_{x}\right)$ and $F\left(\ln \left(z_{y}\right) \mid \mu_{y}\right)=\Phi\left(\left(\ln \left(z_{y}\right)-\mu_{y}\right) / \sigma_{y}\right)$.

Notice that there are no financial markets open here that agents could use to hedge their productivity shocks or those of the foreign country. The equilibrium movements in international prices are an important source of risk-sharing Cole and Obstfeld (1991). One of the key insights of this model will be that the information countries have about each others' productivity changes how they share risk. If we introduce another source of risk sharing, we would obscure that effect.

Information: At the beginning of the period, firms in country $x$ observe their own endowment $z_{x}$ and the mean of their country's endowment $\mu_{x}$. Likewise, agents in country $y$ observe $z_{y}$ and $\mu_{y}$. Furthermore, we assume that both countries know the distribution from which mean productivities are drawn and the 
cross-sectional variance of firm outcomes. In other words, $m_{x}, m_{y}, s_{x}, s_{y}, \sigma_{x}$ and $\sigma_{y}$ are common knowledge.

In addition, agents in country $x$ observe a signal about the $y$-endowment $\tilde{m}_{y}=\mu_{y}+\eta_{y}$ where $\eta_{y} \sim$ $N\left(0, \tilde{s}_{y}^{2}\right)$. Similarly, agents in country $y$ observe a signal about the $x$-endowment $\tilde{m}_{x}=\mu_{x}+\eta_{x}$ where $\eta_{x} \sim N\left(0, \tilde{s}_{x}^{2}\right)$. Let $\mathcal{I}_{x}$ denote the information set of an agent in the home country and let $\mathcal{I}_{y}$ denote the information set of a foreign agent. All home country choices will be a function of the three random variables in the home agents' information set: $\mathcal{I}_{x}=\left\{z_{x}, \mu_{x}, \tilde{m}_{y}\right\}$. Likewise, foreign choices depend on $\mathcal{I}_{y}=\left\{z_{y}, \mu_{y}, \tilde{m}_{x}\right\}$.

Bayesian updating Agents in each country combine their prior knowledge of the distribution of the others' productivity and their signal to form posterior beliefs. By Bayes' law, the posterior probability distribution is normal with mean $\hat{m}$ and variance $\hat{s}^{2}$ given by

$$
\begin{array}{lll}
F\left(\mu_{y} \mid \mathcal{I}_{x}\right)=\Phi\left(\frac{\mu_{y}-\hat{m}_{y}}{\hat{s}_{y}}\right) & \text { where } \quad \hat{m}_{y}=\frac{s_{y}^{-2} m_{y}+\tilde{s}_{y}^{-2} \tilde{m}_{y}}{s_{y}^{-2}+\tilde{s}_{y}^{-2}}, \quad \hat{s}_{y}^{2}=\frac{1}{s_{y}^{-2}+\tilde{s}_{y}^{-2}} \\
F\left(\mu_{x} \mid \mathcal{I}_{y}\right)=\Phi\left(\frac{\mu_{x}-\hat{m}_{x}}{\hat{s}_{x}}\right) \quad \text { where } \quad \hat{m}_{x}=\frac{s_{x}^{-2} m_{x}+\tilde{s}_{x}^{-2} \tilde{m}_{x}}{s_{x}^{-2}+\tilde{s}_{x}^{-2}}, \quad \hat{s}_{x}^{2}=\frac{1}{s_{x}^{-2}+\tilde{s}_{x}^{-2}}
\end{array}
$$

In order to forecast prices, agents will need to forecast the other country's export choices. Since others' export choices depend on their forecasts of one's own endowment, actions will also depend on beliefs about the beliefs of others. According to Bayes' law, these second-order beliefs are

$$
\begin{array}{ll}
F\left(\hat{m}_{x} \mid \mathcal{I}_{x}\right)=\Phi\left(\frac{\hat{m}_{x}-\hat{\hat{m}}_{x}}{\hat{\hat{s}}_{x}}\right) \quad \text { where } \quad \hat{\hat{m}}_{x}=\frac{s_{x}^{-2} m_{x}+\tilde{s}_{x}^{-2} \mu_{x}}{s_{x}^{-2}+\tilde{s}_{x}^{-2}}, \quad \hat{\hat{s}}_{x}^{2}=\frac{\tilde{s}_{x}^{-2}}{\left(s_{x}^{-2}+\tilde{s}_{x}^{-2}\right)^{2}} \\
F\left(\hat{m}_{y} \mid \mathcal{I}_{y}\right)=\Phi\left(\frac{\hat{m}_{y}-\hat{\hat{m}}_{y}}{\hat{\hat{s}}_{y}}\right) \quad \text { where } \quad \hat{\hat{m}}_{y}=\frac{s_{y}^{-2} m_{y}+\tilde{s}_{y}^{-2} \mu_{y}}{s_{y}^{-2}+\tilde{s}_{y}^{-2}}, \quad \hat{\hat{s}}_{y}^{2}=\frac{\tilde{s}_{y}^{-2}}{\left(s_{y}^{-2}+\tilde{s}_{y}^{-2}\right)^{2}}
\end{array}
$$

Note that there is a one-to-one mapping between signals $\tilde{m}$ and posterior beliefs $\hat{m}$. Instead of using signals as a state variable, we will use posterior beliefs, for simplicity and without loss of generality. Thus, we write $\mathcal{I}_{x}=\left\{z_{x}, \mu_{x}, \hat{m}_{y}\right\}$ and $\mathcal{I}_{y}=\left\{z_{y}, \mu_{y}, \hat{m}_{x}\right\} .1$

Price and budget set: Each agent chooses how much to export, $t_{x}$ or $t_{y}$. The relative price $q$ is the number of units of $x$ good required to purchase one unit of $y$ good on the international market. In equilibrium, this price clears the market. As the goods return from the international market to the import destination, a fraction $1 /(1+\tau)$ of the goods are lost as a iceberg cost of trade. An agent who exports $t_{x}$ units of $x$ goods receives $\frac{t_{x}}{(1+\tau) q}$ units of $y$, for immediate consumption (there is no secondary resale market).

\footnotetext{
${ }^{1}$ In fact, all higher orders of beliefs can matter for export choices. But, because there are only two shocks observed by each country, the first two orders of beliefs are sufficient to characterize the entire hierarchy.
} 
We restrict exports and consumption to be non-negative. Therefore the country $x$ budget set is:

$$
\begin{array}{lll}
c_{x} & \epsilon & {\left[0, z_{x}-t_{x}\right]} \\
c_{y} & \epsilon & {\left[0, \frac{t_{x}}{(1+\tau) q}\right]}
\end{array}
$$

and the country $y$ budget set is:

$$
\begin{array}{lll}
c_{x} & \epsilon & {\left[0, \frac{t_{y} q}{1+\tau}\right]} \\
c_{y} & \epsilon & {\left[0, z_{y}-t_{y}\right]}
\end{array}
$$

When the export decision is made, firms do not know the price $q$. It is a random variable whose realization depends on their own (known) aggregate state, on the foreign (unknown) aggregate state, on home beliefs about the foreign state and on foreign beliefs about the home state.

Equilibrium An equilibrium is given by export policy functions for domestic $t_{x}\left(z_{x}, \mu_{x}, \hat{m}_{y}\right)$ and foreign $t_{y}\left(z_{y}, \mu_{y}, \hat{m}_{x}\right)$ countries, aggregate exports $T_{x}\left(\mu_{x}, \hat{m}_{y}\right), T_{y}\left(\mu_{y}, \hat{m}_{x}\right)$, perceived price functions $\tilde{q}\left(\mu_{x}, \mu_{y}, \hat{m}_{x}, \hat{m}_{y}\right)$ for each country and an actual price function $q\left(\mu_{x}, \mu_{y}, \hat{m}_{x}, \hat{m}_{y}\right)$ such that:

1. Given perceived price functions $\tilde{q}\left(\mu_{x}, \mu_{y}, \hat{m}_{x}, \hat{m}_{y}\right)$, export policies maximize expected consumption of every firm in each country. Substituting the budget sets (5) to (8) into $E\left[\left(c_{x}^{\theta}+c_{y}^{\theta}\right)^{1 / \theta}\right]$, we can write this problem as

$$
\begin{gathered}
\left.t_{x}\left(z_{x}, \mu_{x}, \hat{m}_{y}\right)=\arg \max E\left[\left(\left(z_{x}-t_{x}\right)^{\theta}+\left(\frac{t_{x}}{(1+\tau) \tilde{q}\left(\mu_{x}, \mu_{y}, \hat{m}_{x}, \hat{m}_{y}\right)}\right)^{\theta}\right)^{1 / \theta}\right]_{\mathcal{I}_{x}}\right] \\
t_{y}\left(z_{y}, \mu_{y}, \hat{m}_{x}\right)=\arg \max E\left[\left.\left(\left(\frac{t_{y} \tilde{q}\left(\mu_{x}, \mu_{y}, \hat{m}_{x}, \hat{m}_{y}\right)}{1+\tau}\right)^{\theta}+\left(z_{y}-t_{y}\right)^{\theta}\right)^{1 / \theta}\right|^{\prime}\right]
\end{gathered}
$$

Using the conditional densities (1), (2), (4) and (3), we can compute expectations as

$$
\begin{aligned}
& t_{x}\left(z_{x}, \mu_{x}, \hat{m}_{y}\right)=\arg \max \iint\left(\left(z_{x}-t_{x}\right)^{\theta}+\left(\frac{t_{x}}{(1+\tau) \tilde{q}\left(\mu_{x}, \mu_{y}, \hat{m}_{x}, \hat{m}_{y}\right)}\right)^{\theta}\right)^{1 / \theta} d F\left(\mu_{y} \mid \mathcal{I}_{x}\right) d F\left(\hat{m}_{x} \mid \mathcal{I}_{x}\right) \\
& t_{y}\left(z_{y}, \mu_{y}, \hat{m}_{x}\right)=\arg \max \iint\left(\left(\frac{t_{y} \tilde{q}\left(\mu_{x}, \mu_{y}, \hat{m}_{x}, \hat{m}_{y}\right)}{1+\tau}\right)^{\theta}+\left(z_{y}-t_{y}\right)^{\theta}\right)^{1 / \theta} d F\left(\mu_{x} \mid \mathcal{I}_{y}\right) d F\left(\hat{m}_{y} \mid \mathcal{I}_{y}\right)
\end{aligned}
$$

2. The relative price $q$ clears the international market. Since every unit of $x$-good exported must be sold 
and paid for with $y$ exports, and conversely, every unit of $y$ exports must be sold and paid for with $x$ exports, the only price that clears the international market is the ratio of aggregate exports:

$$
q\left(\mu_{x}, \mu_{y}, \hat{m}_{x}, \hat{m}_{y}\right)=\frac{T_{x}\left(\mu_{x}, \hat{m}_{y}\right)}{T_{y}\left(\mu_{y}, \hat{m}_{x}\right)}
$$

where aggregate exports are

$$
\begin{aligned}
& T_{x}\left(\mu_{x}, \hat{m}_{y}\right)=\int t_{x}\left(z_{x}, \mu_{x}, \hat{m}_{y}\right) d F\left(z_{x} \mid \mu_{x}\right) \\
& T_{y}\left(\mu_{y}, \hat{m}_{x}\right)=\int t_{y}\left(z_{y}, \mu_{y}, \hat{m}_{x}\right) d F\left(z_{y} \mid \mu_{y}\right) .
\end{aligned}
$$

3. The perceived and actual price functions coincide:

$$
\tilde{q}\left(\mu_{x}, \mu_{y}, \hat{m}_{x}, \hat{m}_{y}\right)=q\left(\mu_{x}, \mu_{y}, \hat{m}_{x}, \hat{m}_{y}\right) \quad \forall\left(\mu_{x}, \mu_{y}, \hat{m}_{x}, \hat{m}_{y}\right)
$$

\subsection{Characterization of Equilibrium}

Optimal exports The next result shows that within each country, every firm exports the same fraction of their endowment. But the size of that fraction depends on the average aggregate endowment at home, their beliefs about the average endowment abroad and their beliefs about what the other country knows.

Lemma 1 Export policies that are proportional to firm productivity, $t\left(z, \mu_{x}, \hat{m}_{y}\right)=z \Psi\left(\mu_{x}, \hat{m}_{y}\right)$ for home firms and $t\left(z, \mu_{x}, \hat{m}_{y}\right)=z \Gamma\left(\mu_{x}, \hat{m}_{y}\right)$ for foreign firms, are solutions to the problems in (11) and (12).

Thus, aggregate domestic and foreign exports are

$$
\begin{aligned}
& T_{x}\left(\mu_{x}, \hat{m}_{y}\right)=\int z_{x} \Psi\left(\mu_{x}, \hat{m}_{y}\right) d F\left(z_{x} \mid \mu_{x}\right)=e^{\mu_{x}+\frac{1}{2} \sigma_{x}^{2}} \Psi\left(\mu_{x}, \hat{m}_{y}\right) \\
& T_{y}\left(\mu_{y}, \hat{m}_{x}\right)=\int z_{y} \Gamma\left(\mu_{y}, \hat{m}_{x}\right) d F\left(z_{y} \mid \mu_{y}\right)=e^{\mu_{y}+\frac{1}{2} \sigma_{y}^{2}} \Gamma\left(\mu_{y}, \hat{m}_{x}\right),
\end{aligned}
$$

where the last equality holds because $z_{x}$ and $z_{y}$ are lognormal.

Equilibrium relative price Equation (13) tells us that the world market clearing price $q$ is ratio of aggregate $x$ exports to aggregate $y$ exports. Since this ratio arises often, it is useful to define the ratio of the average firm fundamentals $f\left(\mu_{x}, \mu_{y}\right) \equiv E\left[z_{x}\right] / E\left[z_{y}\right]=\exp \left[\left(\mu_{x}-\mu_{y}\right)+1 / 2\left(\sigma_{x}^{2}-\sigma_{y}^{2}\right)\right]$. For example, if countries endowment distributions were symmetric, then $m_{x}=m_{y}$ and $\sigma_{x}=\sigma_{y}$, which would imply that 
$f$ is a lognormal variable, with median value of 1 . Regardless of symmetry, realized equilibrium price is $T_{x}\left(\mu_{x}, \hat{m}_{y}\right) / T_{y}\left(\mu_{y}, \hat{m}_{x}\right)$, which can be rewritten as

$$
q\left(\mu_{x}, \mu_{y}, \hat{m}_{x}, \hat{m}_{y}\right)=f\left(\mu_{x}, \mu_{y}\right) \frac{\Psi\left(\mu_{x}, \hat{m}_{y}\right)}{\Gamma\left(\mu_{y}, \hat{m}_{x}\right)}
$$

Fixed point problems. Equilibrium condition 3 imposes rational expectations, which requires that the agents' beliefs about relative prices coincide with their probability distributions under the true law of motion of the economy. This consistency takes the form of a fixed point problem. Substituting (18) in for $q$ in the expressions for $\Psi$ and $\Gamma$ reveals that the expressions that describe the fraction of output that firms choose to export take the form $\Psi=g_{1}\left(\mathcal{I}_{x}, \Psi, \Gamma\right)$ and $\Gamma=g_{2}\left(\mathcal{I}_{y}, \Psi, \Gamma\right)$. (See appendix for derivation.) In other words, the optimal fraction of exports depends on what firms believe will be the fraction of output that others will export. When the optimal export policy and beliefs about others' export policies coincide, that is an equilibrium. Thus, the equilibrium is described by functions $\Psi$ and $\Gamma$ that solve equations $g_{1}$ and $g_{2}$.

\subsection{Solution with Cobb-Douglas Utility}

Clearly, the form of the utility function and the preference parameters matter here. As an example suppose that instead of CES preferences, we have Cobb-Douglas preferences, which are the limit of the CES preferences as $\theta \rightarrow 0$. In this limit, preferences are

$$
\mathbb{E}[c]=\mathbb{E}\left[c_{x}^{1-\gamma}\left(\alpha c_{y}\right)^{\gamma}\right] .
$$

Substituting in the budget constraint and taking first order conditions for home and foreign exports yields a simple optimal export policy:

$$
t_{x}=\gamma z_{x} \quad t_{y}=\gamma z_{y} \quad c_{x}=(1-\gamma) z_{x} \quad t_{y}=(1-\gamma) z_{y}
$$

The policy is to have a fixed proportion of endowment for consumption of $x$ and the rest to export, regardless of the prices and regardless of information sets. Since each firm's exports are a constant fraction of their output, aggregate exports are a constant fraction of aggregate output. Since this policy is independent of information sets, information globalization has no effect on exports, and subsequently, no effect on international relative prices or risk-sharing. 


\section{Simulation strategy and parameter choice}

We will solve and simulate different versions of the model: (i) full information, where both countries know their own productivity and the other country's productivity exactly $\left(\hat{m}_{x}=\mu_{x}\right.$ and $\left.\hat{m}_{y}=\mu_{y}\right)$; (ii) no information, where each country knows its own productivity and since neither country gets any signal, their beliefs about the other country's productivity are given by the unconditional distribution $\left(\hat{m}_{x}=m_{x}\right.$ and $\hat{m}_{y}=m_{y}$ ); and finally (iii) noisy signals, where each country knows its own productivity and receives signals about the other country's productivity. In this last case we will solve and simulate the model for various levels of signal precision, always keeping the precision symmetric across countries.

For each information model, we solve the fixed point problem by iterating on the export policy functions $\Psi$ and $\Gamma$ which are approximated using linear splines. For each country we define grids for their two states: aggregate productivity and posterior mean of foreign productivity. We also define grids for foreign productivity and second order beliefs that countries use to evaluate their perceived price function. Expectations with respect to foreign productivity and second order beliefs are computed using Gaussian quadrature.

Once we have solved the fixed point problem, we simulate the repeated economy for $T=100,000$ periods and compute average statistics across simulations. We first draw a series of aggregate productivities and fix it across information models. Then for each information model we generate posterior means of foreign productivity by drawing signals centered at the realized aggregate productivities and with precision determined by the model at hand. See Appendix B for more details.

Parameters Table 1 describes the parameters we use to simulate the models and how they are chosen or calibrated. The unconditional mean of aggregate productivity $m$ and the dispersion of firm productivity $\sigma$ only appear in the solution as differences between home and foreign values. Only the differences $m_{x}-m_{y}$ or $\sigma_{x}-\sigma_{y}$ affect the export shares or the relative prices. The absolute quantities produced and traded do depend on these parameters, but not any relative quantities or prices. Since the question of fundamental asymmetry between two countries and its effect on trade is not the focus of this paper, we assume that there is no difference in the distribution of fundamentals by imposing symmetry: $m_{x}=m_{y}$ and $\sigma_{x}=\sigma_{y}$. We normalize $m=0$ and $\sigma=\sqrt{2}$ so that the mean of aggregate (log) endowment is unity: $\mathbb{E}\left[\log f_{x}\right]=m_{x}+\frac{1}{2} \sigma_{x}^{2}=1$. To set volatility of the aggregate productivity shocks, we note that it is the ratio of signal to aggregate dispersion what matters for outcomes $\frac{\tilde{s}}{s}$. Since we will vary signal precision across simulations, we assume symmetry and normalize the volatility of aggregate shocks to unity $\left(s_{x}=s_{y}=1\right)$. We set $\theta$ equal to 0.75 that implies an elasticity of substitution across the two consumption goods of $\nu=\frac{1}{1-\theta}=4$, which is a standard value in the trade literature. Finally, the precision of the signals that each country observes about the other's 
productivity $\tilde{s}^{-2}$ and the iceberg costs $\tau$ are varied across simulations in the range $[0, \infty]$.

\section{Table 1: Summary of Model Parameters}

\begin{tabular}{|c|c|c|c|c|}
\hline Parameter & $m_{x}=m_{y}$ & $\sigma_{x}=\sigma_{y}$ & $s_{x}=s_{y}$ & $\theta$ \\
\hline Value & 0 & $\sqrt{2}$ & 1 & 0.75 \\
\hline
\end{tabular}

\section{Results}

Our main findings are that information frictions, meaning less precise signals about foreign productivity, can increase trade, lower utility, and decrease risk. In the subsections that follow, we illustrate each of these results in our calibrated model, propose explanations for why each effect arises, and look for additional evidence in the model and simulations to support our explanation.

We begin by reporting some basic summary statistics for three versions of the model described above (Table 2). In the model with no information, neither country gets any signal about the other's productivity. In this model, exports are a large fraction of the endowment on average, but a smaller total amount, which is quite stable. In the model with full information, both countries know their own productivity and the other country's productivity exactly $\left(\hat{m}_{x}=\mu_{x}\right.$ and $\left.\hat{m}_{y}=\mu_{y}\right)$. We see that exports are a smaller fraction of the endowment on average, a moderate total amount, but that total amount of exports is very volatile. The noisy signals model is run for various levels of signal precision, always keeping the precision symmetric across countries. In this model, agents export a moderate fraction of the endowment, the largest total amount of exports, and exports are almost as much volatile as in the full-information case.

In all the variations of the information models, we have set the trade cost to zero. We also present results of the impact of larger trade costs for the perfect information case.

\subsection{Trade Volume}

The question posed at the start of the paper is whether information frictions and trade frictions such as iceberg costs have similar effects on international trade. To answer this question, we start by looking at trade volume. To normalize the volume of trade, we consider the ratio of exports to domestic consumption of the home good as our measure of the volume of trade. We call this trade share:

Trade Share $_{x} \equiv \frac{t_{x}}{c_{x}}$ 
Table 2: Simulation Results

\begin{tabular}{lccc}
\hline \hline & No info & Noisy signals & Full info \\
& $\tilde{s}^{-2}=0$ & $\tilde{s}^{-2}=2$ & $\tilde{s}^{-2}=\infty$ \\
\hline Exports & 16.01 & 5.58 & 1.76 \\
& $(765)$ & $(64.7)$ & $(2.54)$ \\
\hline Consumption & 1.42 & 1.52 & 1.58 \\
& $(0.24)$ & $(0.86)$ & $(1.33)$ \\
\hline Retal Exports & 1.28 & 1.20 & 1.07 \\
& $(1.21)$ & $(0.88)$ & $(0.39)$ \\
\hline \hline
\end{tabular}

The moments reported are the average quantity across many simulations with independent random draws of productivity and signal noise. The moments in parentheses are the standard deviation across simulations. Total endowment in each country has an average of 4.48 and a standard deviation of 5.79 .

It is defined analogously for country $y$.

First, we simulate a benchmark version of the model where there is perfect information $\left(\tilde{s}^{-2}=\infty\right)$, but a fraction of all exports are lost $(\tau>0)$. In the left side of figure 1, moving to the right represents lower trade costs. We see that lowering trade costs increases the fraction of the endowment traded. This is not surprising. But it offers a stark contrast to the effect of lower information frictions.

The key result is that information globalization can decrease the trade share. Put differently, trade share is decreasing in signal precision, for a large range of parameters. Figure 1 plots the average quantities for many different models, as signal precision increases. The first panel shows that the fraction of the endowment exported $E[\Psi]$ declines monotonically in signal precision. In contrast, the total units exported rise in signal precision initially and then fall off as signal precision increases further. The same moments for the foreign country exhibit the same patterns.
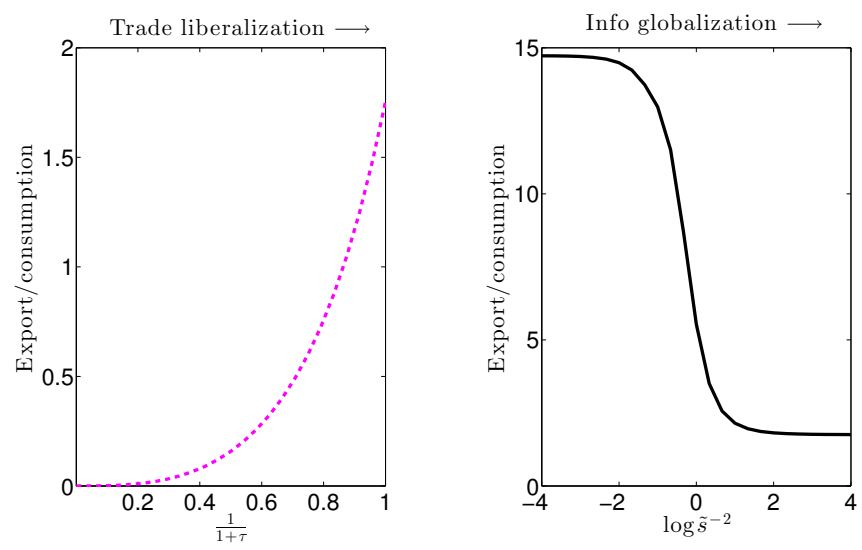

Figure 1: Smaller iceberg cost (left) increases the trade share while a smaller information friction (right side) decreases trade share. 
This counter-intuitive result, that better information reduces the trade share, arises because of secondorder beliefs. When home output is low, the home good is scarce and thus the relative price of home goods is high, making the relative price of foreign goods low. If the foreign country anticipates this low relative price, they'll export less. This reduction in foreign exports makes home goods relatively more abundant and thus offsets some of the increase in the relative price of home goods. If the home firms anticipate that foreigners will forsee low home output, export less and mitigate the increase in home relative price, the home firms will choose a lower export share. If foreigners have precise information, but the home firms don't know this (fixed second-order belief precision), the home firms will not lower their export share and the effect disappears.

Of course, this mechanism should produce the opposite effect when home output is high. Home relative prices will be low, foreign high. Anticipating this, foreigners export more, which offsets the decline in home relative prices. Thus, when home firms know that foreigners are well-informed about their economic state, they export more in booms then they would without that precise foreign information. But because consumption is low in the low home output states, changes in exports have a large effect on the export/consumption share. In high states, second order beliefs increase exports, but have less of an effect on the average export/consumption ratio.

This second-order belief effect shows up in the optimal export first-order condition. By replacing the export volume with the endowment times export share, $t_{x}=z_{x} \Psi$, we can re-express the home export choice problem (9) as

$$
\max _{\Psi} z_{x} \mathbb{E}\left[\left((1-\Psi)^{\theta}+\left(\frac{\Psi}{(1+\tau) q}\right)^{\theta}\right)^{1 / \theta} \mid\left(\mu_{x}, \hat{m}_{y}\right)\right]
$$

Taking a first-order condition with respect to $\Psi$ yields the following solution

$$
\mathbb{E}\left[\left(\frac{C}{1-\Psi\left(\mu_{x}, \hat{m}_{y}\right)}\right)^{1-\theta} \mid\left(\mu_{x}, \hat{m}_{y}\right)\right]=\mathbb{E}\left[\left(\frac{C}{\Psi\left(\mu_{x}, \hat{m}_{y}\right)}\right)^{1-\theta} \frac{1}{(1+\tau)^{\theta} q^{\theta}} \mid\left(\mu_{x}, \hat{m}_{y}\right)\right]
$$

which can be re-arranged as

$$
\left(\frac{\Psi\left(\mu_{x}, \hat{m}_{y}\right)}{1-\Psi\left(\mu_{x}, \hat{m}_{y}\right)}\right)^{1-\theta}=\underbrace{\mathbb{E}\left[q^{-\theta} \mid\left(\mu_{x}, \hat{m}_{y}\right)\right]}_{I}+\underbrace{\frac{\mathbb{C}\left[C^{1-\theta}, q^{-\theta} \mid\left(\mu_{x}, \hat{m}_{y}\right)\right]}{\mathbb{E}\left[C^{1-\theta} \mid\left(\mu_{x}, \hat{m}_{y}\right)\right]}}_{\frac{I I}{I I I}}
$$

Since we assumed that $\theta<1$, the left side of the equation is increasing in the export share $\Psi$. Thus, anything that increases the right side will increase the equilibrium trade share. The right side of the equation is the sum of two terms, labelled I and II/III. The first term is the expected relative price, raised to the power 
$-\theta$. Raising the price to a negative power makes $q^{-\theta}$ high when the relative price of home goods is high. Raising the price to an exponent between $(-1,1)$ weights low $q$ 's (high home good prices) more than high $q$ 's (low home good prices) in the expectation. In other words, this makes the trade share $\Psi$ more sensitive to changes in relative price when the home relative price is high than when it is low.

In figure 2 (left panel), we see the second-order belief effect described above. In states where home productivity is low (dashed line), home's expectation of low foreign exports because of foreigners' beliefs about low home exports reduces home export share as signal precision rises. In average-productivity states, signal precision has no effect on the trade share. In states where home productivity is high (dotted line), home's expectation of high foreign exports because of foreigners' beliefs that home exports will be high increases home exports as signal precision rises. But this increase in trade share is modest.
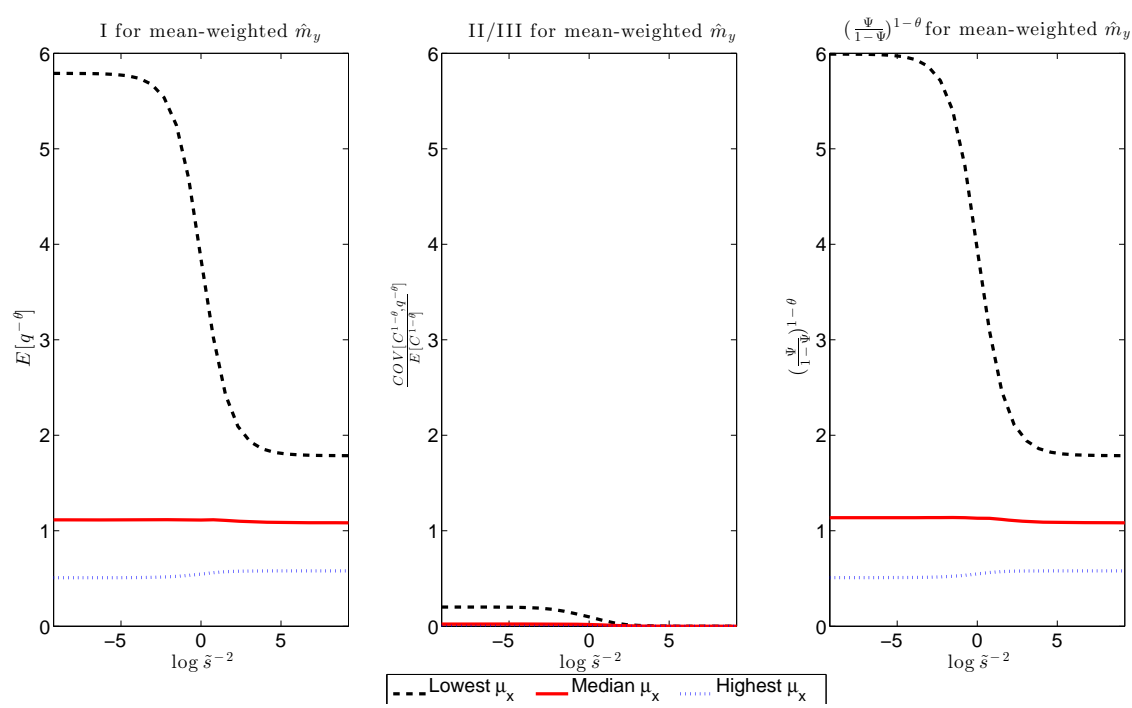

Figure 2: Terms from the first-order condition for different levels of information precision $\tilde{s}^{-2}$. Most of the decline in trade share comes from term I.

The second term (II/III) depends on expected consumption, expected relative price and the covariance between the two. But it turns out to be relatively insensitive to signal precision (figure 2, middle panel).

If this rotation of the productivity-price relationship were symmetric, there would be no effect on the average amount of trade. Countries with more precise information about each other trade less in lowproductivity states but more in high productivity states. When the consumption aggregator is Cobb-Douglas, these two effects offset each other exactly and the average level of trade does not change with information precision. But when goods are imperfect substitutes, the fall in trade in low-productivity states is larger than the rise in high-productivity states. This comes from an additional precautionary trading effect that prompts more trade when expected consumption is low and the terms of trade are most uncertain. 
In a consumption-savings model, future income shocks make the marginal utility of goods carried into future states uncertain. When utility has a positive third derivative, agents are more risk-averse at low levels of wealth than they are at high levels of wealth. So, when wealth is low, they are very averse to the risk of future low consumption states and they save more. A similar effect is at work here. When productivity is low, agents cannot export many units of $x$, but they fear that a low relative price realization will leave them with a very small $c_{y}$. To hedge against this risk, they export more. Of course this lowers $c_{x}$, but that is a certain effect. $c_{x}$ is not random. The strong risk aversion prompts more exports. When information about foreign productivity is noisier (larger information friction), relative prices are more uncertain and the desire to export for precautionary reasons is stronger. This is the force that makes noisy information correspond with high exports and thus causes the export share to fall as information frictions diminish.

Turning off the second-order belief effect To see that it is really second-order beliefs that are at the heart of the negative relationship between information and average trade shares, we turn off movements in second-order beliefs. Then we check if the trade share still decreases in information precision, holding second order beliefs fixed. To do this experiment, we vary the precision of both countries' information, but we hold fixed the home country beliefs about foreign signal precision. This fixes second-order beliefs: home beliefs about what foreigners believe about home country productvity. But it allows all first-order beliefs to vary: Each country knows that the precision of their beliefs about the other country is rising. This is violating the assumption of rational expectations. That does not make this a desirable benchmark model. Instead, it is simply an experiment that isolates one single channel to see if that channel is responsible for the decline of trade share in signal precision.

Figure 3 reveals that when the precision of home second-order beliefs is held fixed, the average trade share no longer declines, even if true signal precision increases for both countries. It is not an increase in the precision of one's own signal that makes trade share decline. Rather, it is the increase in one beliefs about the other country's signal precision that makes a country reduce the fraction of output it exports on average, and particularly in low-productivity states. The message from these results is that more precise information reduces the average export share because of what one country anticipates that a well-informed foreign trade partner will do to worsen their terms of trade, in times when the home country productivity is low.

How can the trade share fall while total exports rise? One puzzling feature of these results is that when signals are very noisy (low $\tilde{s}^{-2}$ ), the fraction of the endowment exported falls, while the total units exported rises, on average. Since the endowment is drawn from the same distribution in both models, these results appear contradictory. But in fact, it comes from a change in covariance. We can write the amount 


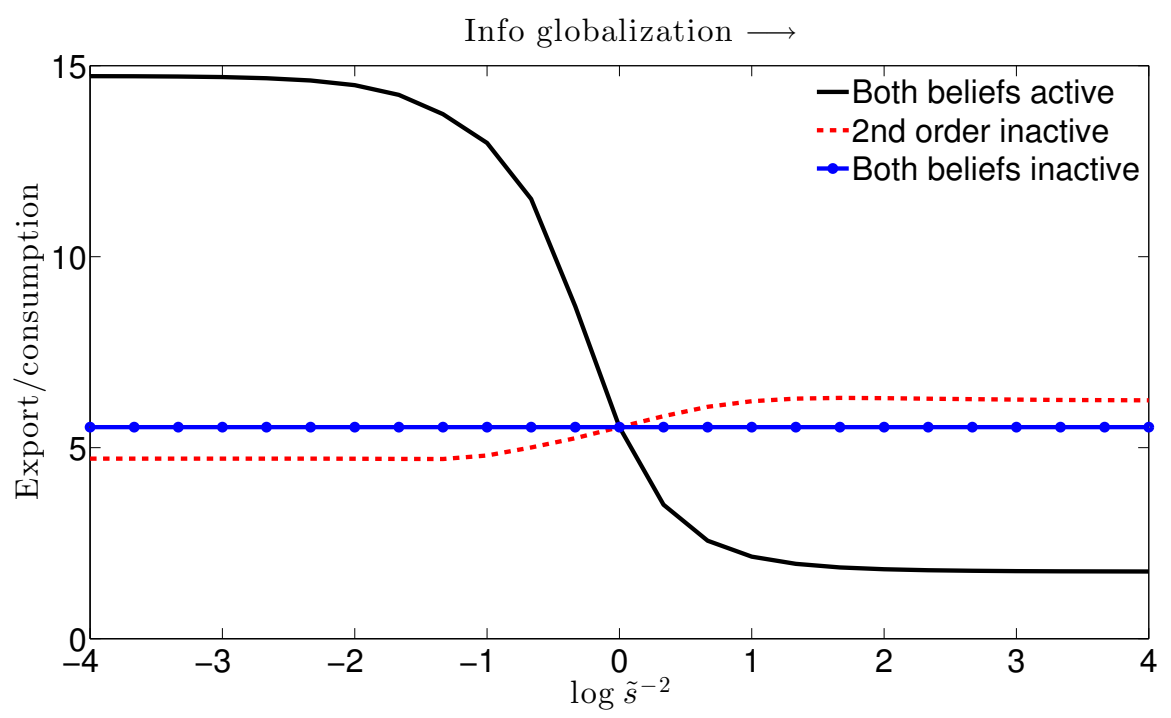

Figure 3: Turning off the change in second order beliefs. Increases in signal precision no longer reduce the trade share.

of $x$ goods exported as the fraction of the endowment exported, times the endowment: $T_{x}=f_{x} \Psi\left(\mu_{x}, \hat{m}_{y}\right)$. Taking an expectation yields

$$
E\left[T_{x}\right]=E\left[f_{x}\right] E\left[\Psi\left(\mu_{x}, \hat{m}_{y}\right)\right]+\operatorname{Cov}\left(f_{x}, \Psi\left(\mu_{x}, \hat{m}_{y}\right)\right)
$$

When noisy signals are introduced, $E\left[T_{x}\right]$ rises, $E\left[f_{x}\right]$ is constant and $E\left[\Psi\left(\mu_{x}, \hat{m}_{y}\right)\right]$ falls. That is only possible if $\operatorname{Cov}\left(f_{x}, \Psi\left(\mu_{x}, \hat{m}_{y}\right)\right)$ rises. The simulation results confirm that this covariance rises in signal precision.

This covariance is at the heart of most of the results in the paper. It is the covariance between home aggregate productivity and the share of home goods exported. When signal precision rises, the fact that the other country anticipates periods of high home output and high foreign relative price makes the foreign country export more. When foreigners export more, it increases the relative price of the home good and induces the home country to export even more. That is why $\operatorname{Cov}\left(f_{x}, \Psi\left(\mu_{x}, \hat{m}_{y}\right)\right)$ rises in signal precision. It is the same reason why information increases export volatility and consumption risk.

\section{$3.2 \quad$ Risk-Sharing}

When the iceberg trade cost $\tau$ falls, risk-sharing improves. One metric of risk-sharing in a model is the correlation of utilities of each country's representative agent. When risk is shared, a productivity shock that hits one country is transmitted to the other country, resulting in utility correlation. The mechanism that transmits shocks between countries is the relative price. When the foreign country's endowment is small, 
their exports are low and the relative price of foreign goods is high. This makes the relative price of home goods low. Because home good exports earn little in return, home composite consumption falls and home utility is low. As trade costs diminish, prices becoming a more effective hedge for productivity risk and risk-sharing improves. None of this is a surprise. But once again, it contrasts starkly with the effect of information frictions.
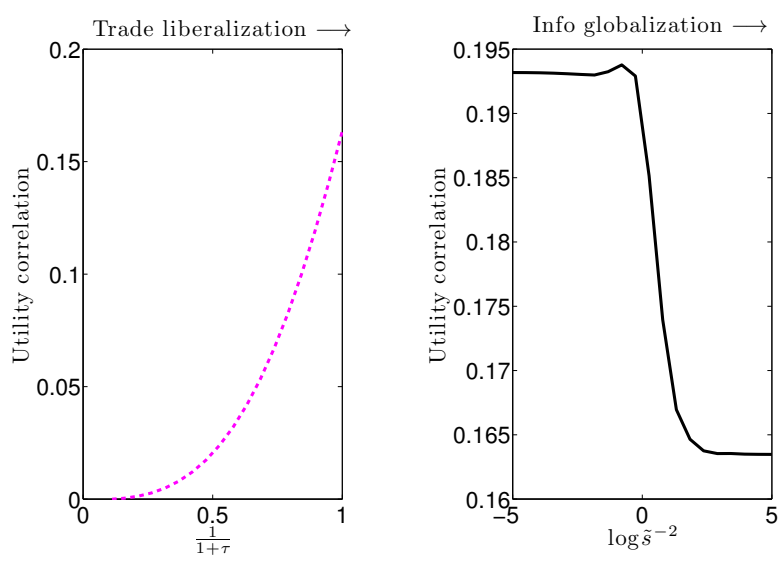

Figure 4: Information reduces risk-sharing.

The second result of the paper is that when two countries have more precise information about each others' output, they share less risk. To illustrate this effect, Figure 4 plots the correlation of realized utility in the two countries. In the left panel, trade costs are diminishing and utility correlation is increasing. In the right panel, signal precision is increasing and utility correlation decreases (in most of the space). In other words, trade liberalization improves risk sharing while information globalization inhibits risk sharing.

The mechanism by which information worsens risk-sharing is that it makes the relative international price less flexible. Define an international price index as $Q \equiv\left(1+q^{\theta /(1-\theta)}\right)^{(1-\theta) / \theta}$. This is the standard CES price aggregator. Since $x$ is a numeraire good with price 1, the relative price of the home good to the composite consumption good is $1 / Q$. Figure 5 shows that when information is noisy, the relative price looks like a very flexible price and it absorbs much of the risk of changes in productivity. As information becomes more precise, the resulting prices look more like sticky prices, in that they move less, absorb less risk and cause real quantities to fluctuate more. Again, the effect of information globalization is the opposite of trade liberalization.

A strategic games interpretation Another way of understanding this effect is that information is allowing countries to export in a more coordinated way. If the home country gets a positive productivity shock, but the foreign country does not know this, the foreign country will export the normal amount while 

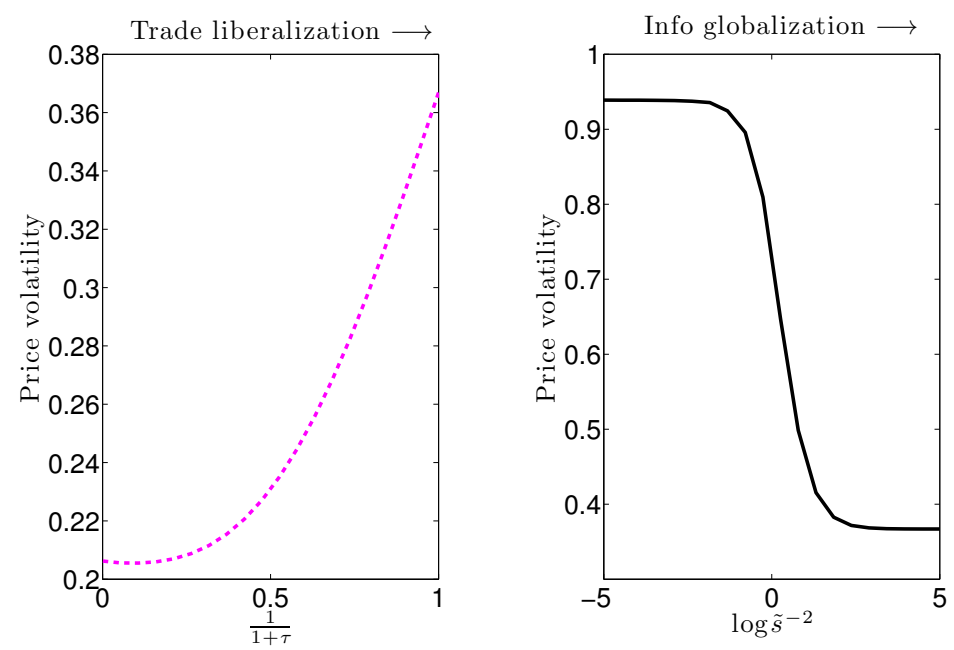

Figure 5: Information globalization makes international prices less flexible.

home country exports will be high. Because home goods are abundant and foreign goods are scarce in the international market, the relative price of home goods is low. The low relative price makes the positive productivity shock less beneficial for total consumption that it otherwise would have been, absent the relative price change. But conversely when home productivity is low, home goods are scarce on the international market and their relative price is high. This high relative price allows total consumption to be higher than it would have been, absent the relative price change. In other words, relative price changes are an effective hedge for productivity risk.

But having information about the other country's productivity eliminates some of the ability for countries to share risk. If the foreign country knows that the home country's productivity is high, they know that the home country will export lots and that the home relative price will be low. But this means that the foreign relative price is high, which prompts the foreign country to export more. This leads exports to be more correlated in the presence of more precise information. But it also counteracts some of the decline in the home good's relative price. Thus, aggregate consumption for the home country is higher. When the foreigners know that home has a low productivity shock, they anticipate that home goods will be scarce and expensive on the international market. Therefore, they expect a low relative price for foreign goods and thus export less as well. The lower exports of foreign goods counteracts some of the rise in the relative price of home goods. Because home goods fetch a lower relative price, home total consumption is lower than it would have been if the foreign country had not known about their shock. Since consumption is higher in high-productivity states and lower in low-productivity states, consumption risk rises with information precision. 
A finance interpretation The idea that information inhibits risk-sharing is similar in spirit to the Hirshleifer (1971) effect in asset pricing. In that setting, when traders get information about the payoff of a risk asset before they trade, average utility declines. The reason is that the information reduces the set of outcomes agents can contract on. Gamblers cannot bet on the outcome of a race that is known. So revealing the outcome of a race prevents them from being able to contract on its outcome. In asset markets, revealing payoff information will increase or decrease the price. What that information is incorporated into the price, it will make the investors endowed with the asset better or worse off. It creates utility risk for them. They cannot share that risk if they are caught holding the asset at the time when information is revealed. In our trade model, we don't let firms write risk-sharing contracts. But the relative price is a mechanism for sharing risk. What that price incorporates more information, it shares less risk between the trading counter-parties, just like in Hirschleifer's model.

\subsection{Consumption and Utility}

The consumption or utility effect of reducing trade costs is straightforward. When trade is less costly, countries export more, consume less of their home good and increase composite consumption by achieving a more balanced consumption bundle. Our simulation results confirm that all three are monotonic effects.
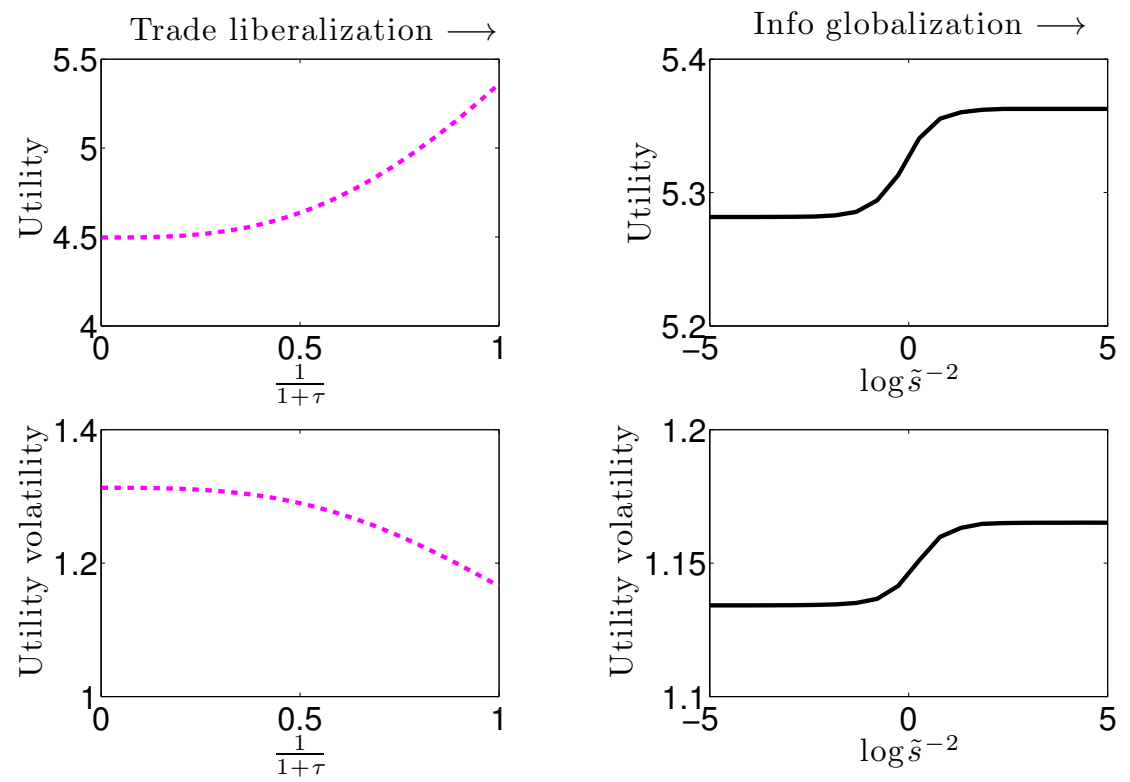

Figure 6: Trade liberalization and information globalization both increase average utility. But information also increases utility volatility.

More signal precision always increases the average consumption of the composite good (expected utility) 
because it allows for better coordination of exports between countries. To understand this effect, we can look at a second order Taylor approximation to the utility function around the point $\left(\mathbb{E}\left[c_{x}\right], \mathbb{E}\left[c_{y}\right]\right)$, which is given by

$$
\mathbb{E}[c] \approx \bar{c}\left\{1+\frac{(1-\theta)}{2}\left(\frac{\mathbb{E}\left[c_{x}\right]}{\bar{c}}\right)^{\theta}\left(\frac{\mathbb{E}\left[c_{y}\right]}{\bar{c}}\right)^{\theta}\left[2 \frac{\mathbb{C}\left[c_{x}, c_{y}\right]}{\mathbb{E}\left[c_{x}\right] \mathbb{E}\left[c_{y}\right]}-\mathbb{C V}\left[c_{x}\right]^{2}-\mathbb{C V}\left[c_{y}\right]^{2}\right]\right\}
$$

where $\bar{c} \equiv c\left(\mathbb{E}\left[c_{x}\right], \mathbb{E}\left[c_{y}\right]\right)$ is the certainty equivalent. This expression shows that utility is increasing in the covariance between the consumption goods, $\mathbb{C}\left[c_{x}, c_{y}\right]$, and this covariance increases when trade is more coordinated (high $\operatorname{corr}\left(T_{x}, T_{y}\right)$ ). More precise information about foreign productivity leads countries to choose export quantities that are more positively correlated. This trade coordination is what explains the higher average level of composite consumption.

In contrast, more precise information about foreign productivity has a non-monotonic effect individually on both the quantity of home goods and the quantity of foreign goods consumed. The most dramatic effect comes from moving from no information $\left(\tilde{s}^{-2}=0\right)$ to noisy signals where $\tilde{s}^{-2}=1$. It turns out that this level of signal precision is the level that makes second-order beliefs most uncertain. Second order beliefs are one country's beliefs about the other's beliefs, $\hat{\hat{m}}$ in the model. When countries have no informative signals, each country knows that the other country's beliefs are the prior mean of productivity. There is no uncertainty about this. When each country has perfect information about the other's productivity, then each knows that the other's beliefs correspond to the true state. Again, there is no uncertainty about second-order beliefs. But when there are noisy signals, because neither country knows exactly what signal the other observed, they don't know what the other country's beliefs are about their productivity. Thus, there is second-order uncertainty. This uncertainty reaches its maximum when signals are prior beliefs are equally precise, at $\tilde{s}^{-2}=1$. This is also the point where home good consumption reaches its minimum and foreign good consumption reaches is maximum.

\subsection{Sensitivity Analysis}

Since the elasticity of substitution is a key parameter in many theories of trade, we explore its effect on our results here (Figure 7). Also, since the degree of aggregate volatility is also the prior uncertainty of the key random variable, we explore increasing or decreasing its value as well (Figure 8).

For the parameter $\theta$ that governs intertemporal elasticity, we explored $0.01,0.2$ and 0.75 . These impliy intertemporal elasticities $(1 / 1-\theta)$ of 1.01 , which is almost Cobb-Douglas utility, 1.25 and 4 , which is a value commonly used in the macro trade literature. We see that while the effect on trade share is quite large for the elasticity of 4 , it falls dramatically as preferences become less elastic and approach Cobb-Douglas. 

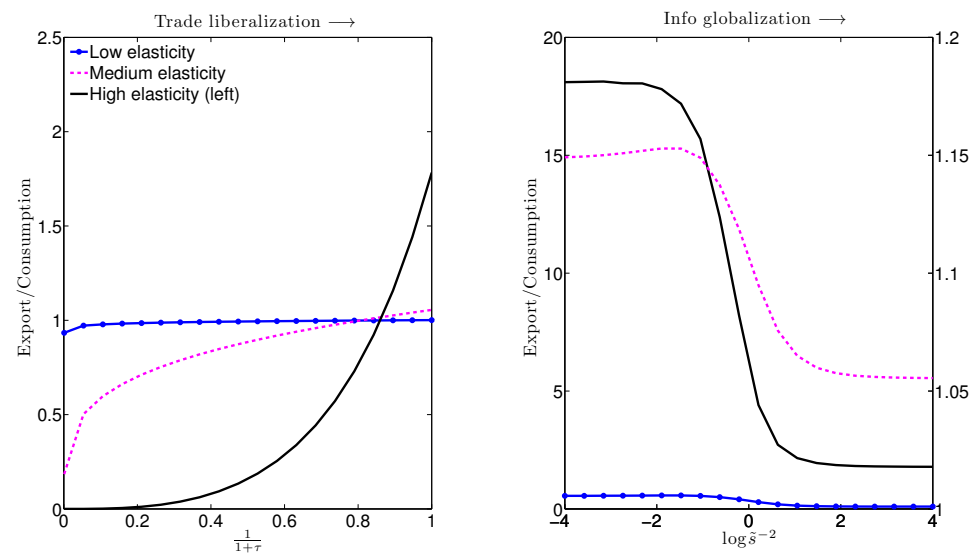

Figure 7: The elasticity of substitution governs the magnitude of the trade effect, but not its direction.

We know that in the Cobb-Douglas case, countries always export a fixed fraction of their endowment and our effect disappears completely. We have work in progress that attempts to solve the model to explore elasticities lower than 1.
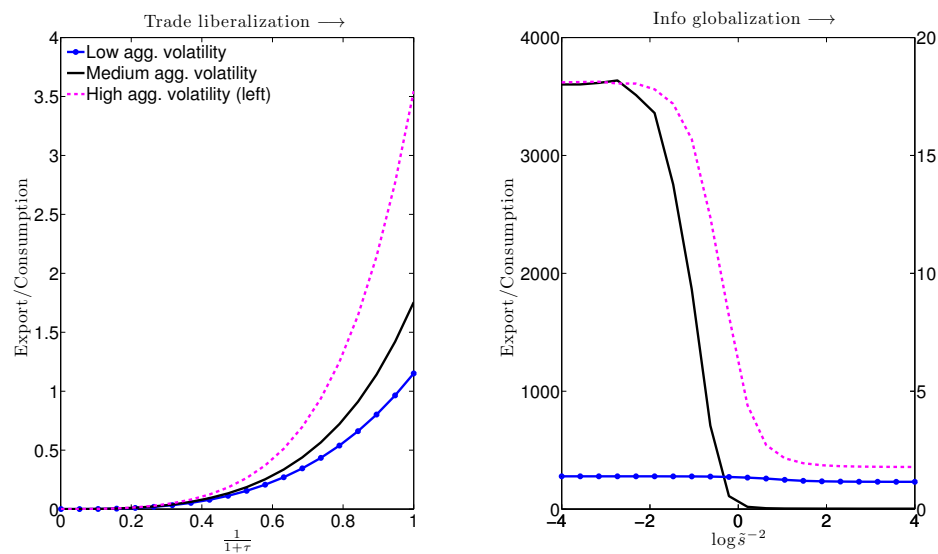

Figure 8: The effect of information on the trade share is largest in high and medium-volatility environments.

For the parameters $s_{x}$ and $s_{y}$ that govern the standard deviation of the aggregate endowment shocks, we explore 0.5, 1 (our benchmark case) and 1.5. Aggregate volatility and information globalization interact in a way that is non-monotonic. For low volatility, relative prices are very predictable, information has little effect because there is little uncertainty to resolve anyway, and the effect of information on trade share vanishes. For medium volatility, the effect is largest. For high volatility, the effect is slightly less than for the benchmark value. If aggregate shocks are extremely uncertain, one signal does little to resolve risk.

In sum, we find that neither changes in the elasticity of substitution nor changes in the volatility of aggregate shocks reverses the effect of information globalization on the trade share. But both can have large 
consequences for the magnitude of the effect.

\subsection{Introducing instruments that share international risk}

So far, we have assumed away all instruments that agents might use to share international risk. Exchange rate futures, international equity holdings, profit-sharing contracts, secondary goods markets, all could help to share international risk and undermine some of the effects we have identified in this paper. Does that make the paper's results less relevant?

We started out wanting to understand what the effect of reductions in international information asymmetry might be on trade. If we start from a setting where perfect risk sharing makes information unnecessary, then of course, we cannot say much about the effect of information frictions. Instead, we give information its best shot to facilitate trade, by considering a world where the inability to share risk makes learning about foreign shocks very valuable. And yet, we still find that information globalization reduces trade and undermines risk-sharing.

If we did include a complete set of risk-sharing instruments and allowed agents to contract before signals were observed, we could achieve perfect risk sharing for any information structure. But even in this environment, our main point is still true, that the effects of information frictions (here no effect) is quite different from the effect of a proportional trade cost, which would still affect trade volume in this setting.

Finally, our results in progress quantify the utility in a constrained planner's problem where the planner ca choose each country's exports, subject to the information that country has available. This socially optimal policy an its associated utility give us some idea of what can be achieved with a limited set of financial instruments.

\section{Conclusions}

When two countries have more precise information about the other country's productivity it can decrease the fraction of the endowment that they trade and make their consumption and trade more volatile. This effect is very different from that of an iceberg cost. There are other types of information frictions that may consistently impede trade, such as matching frictions or firm-specific unknown variables. But uncertainty about aggregate productivity has a more subtle effect on trade, risk and utility than has been previously understood. 


\section{References}

Allen, T. (2013): "Information Frictions in Trade," Northwestern University Working Paper.

Anderson, J., And E. VAn Wincoop (2004): "Trade Costs," Journal of Economic Literature, 42(3), $691-751$.

Cole, H., And M. Obstfeld (1991): "Commodity Trade and International Risk Sharing: How Much Do Financial Markets Matter?," Journal of Monetary Economics, 28, 3-24.

Eaton, J., M. Eslava, C. Krizan, M. Kugler, and J. Tybout (2011): "A Search and Learning Model of Export Dynamics," Working Paper.

Hirshleifer, D. (1971): "The private and social value of information and the reward of inventive activity," American Economic Review, 61, 561-574.

Obstfeld, M., and K. Rogoff (2000): "The Six Major Puzzles in International Macroeconomics: Is There a Common Cause?," Working Paper 7777, National Bureau of Economic Research.

Petropoulou, D. (2011): "Information Costs, Networks and Intermediation in International Trade," LSE Working Paper.

Portes, R., and H. Rey (2005): "The Determinants Of Cross-Border Equity Flows," Journal of International Economics, 65(2), 269-296.

RAUCh, J., AND J. WATSON (2004): "Network Intermediaries in International Trade," Journal of Economics and Management Strategy, 13(1), 69-93.

Steinwender, C. (2014): "Information Frictions and the Law of One Price: When the States and the Kingdom Became United,” LSE job market paper. 


\section{A Proofs}

\section{A.1 Preliminaries}

Notation: For each firm, we define the utility-and-trade-friction adjusted price aggregator as:

$$
Q(z, \mu, \hat{m} ; p, s) \equiv\left[\mathbb{E}\left[\lambda(z, \mu, \hat{m})^{\theta} \mid \mathcal{I}\right]^{\frac{1}{\theta-1}}+\mathbb{E}\left[(\lambda(z, \mu, \hat{m}) s p)^{\theta} \mid \mathcal{I}\right]^{\frac{1}{\theta-1}}\right]^{\frac{\theta-1}{\theta}}
$$

where $(z, \mu, \hat{m})$ is the state of the firm, $\mathcal{I}$ is her information set, $p>0$ are the country's terms of trade, $s \in[0,1]$ is a trade cost and $\lambda(z, \mu, \hat{m}) \equiv c(z, \mu, \hat{m})^{\frac{1-\theta}{\theta}}$ is a measure of firm's utility. Also denote $\bar{\lambda}(z, \mu, \hat{m}) \equiv \mathbb{E}\left[\lambda(z, \mu, \hat{m})^{\theta} \mid \mathcal{I}\right]^{\frac{1}{\theta}}$. Each firm will aggregate prices using this function evaluated at the corresponding terms of trade and trade costs faced by its country. Note that this price index is firm specific.

Optimal exports of home country The maximization problem for the $x$ country and its FOC are:

$$
\begin{gathered}
V\left(z_{x}, \mu_{x}, \hat{m}_{y}\right)=\max _{t_{x}} \mathbb{E}\left[\left(\left(z_{x}-t_{x}\right)^{\theta}+\left(\frac{t_{x}}{(1+\tau) q}\right)^{\theta}\right)^{1 / \theta} \mid \mathcal{I}_{x}\right] \\
E\left[\frac{1}{\theta}\left(\left(z_{x}-t_{x}\right)^{\theta}+\left(\frac{t_{x}}{(1+\tau) q}\right)^{\theta}\right)^{(1-\theta) / \theta}\left(-\theta\left(z_{x}-t_{x}\right)^{\theta-1}+\theta \frac{t_{x}^{\theta-1}}{(1+\tau)^{\theta} q^{\theta}}\right) \mid \mathcal{I}_{x}\right]=0
\end{gathered}
$$

Let $\lambda\left(z_{x}, \mu_{x}, \hat{m}_{y}\right) \equiv c\left(z_{x}, \mu_{x}, \hat{m}_{y}\right)^{\frac{1-\theta}{\theta}}$, write first term as $\lambda\left(z_{x}, \mu_{x}, \hat{m}_{y}\right)^{\theta}=c\left(z_{x}, \mu_{x}, \hat{m}_{y}\right)^{1-\theta}$ and break the expectation:

$$
E\left[\frac{t_{x}^{\theta-1}}{(1+\tau)^{\theta} q^{\theta}} \lambda\left(z_{x}, \mu_{x}, \hat{m}_{y}\right)^{\theta} \mid \mathcal{I}_{x}\right]=\left(z_{x}-t_{x}\right)^{\theta-1} E\left[\lambda\left(z_{x}, \mu_{x}, \hat{m}_{y}\right)^{\theta} \mid \mathcal{I}_{x}\right]
$$

Pulling out the non random term $t_{x}$ we get:

$$
\left(\frac{t_{x}}{z_{x}-t_{x}}\right)^{\theta-1}=\frac{E\left[\lambda\left(z_{x}, \mu_{x}, \hat{m}_{y}\right)^{\theta} \mid \mathcal{I}_{x}\right]}{E\left[\left(\frac{\lambda\left(z_{x}, \mu_{x}, \hat{m}_{y}\right)}{(1+\tau) q}\right)^{\theta} \mid \mathcal{I}_{x}\right]}
$$

Rearranging and using the definition of the price aggregator, we get an implicit expression for optimal exports $t_{x}$ :

$$
\begin{aligned}
t_{x}\left(z_{x}, \mu_{x}, \hat{m}_{y}\right) & =\frac{\mathbb{E}\left[\lambda\left(z_{x}, \mu_{x}, \hat{m}_{y}\right)^{\theta} \mid \mathcal{I}_{x}\right]^{\frac{1}{\theta-1}}}{\mathbb{E}\left[\lambda\left(z_{x}, \mu_{x}, \hat{m}_{x}\right)^{\theta} \mid \mathcal{I}_{x}\right]^{\frac{1}{\theta-1}}+\mathbb{E}\left[\left(\frac{\lambda\left(z_{x}, \mu_{x}, \hat{m}_{x}\right)}{(1+\tau) q}\right)^{\theta} \mid \mathcal{I}_{x}\right]^{\frac{1}{\theta-1}}} \\
& =\left(\frac{\left.\left[\mathbb{E}\left[\lambda\left(z_{x}, \mu_{x}, \hat{m}_{x}\right)^{\theta} \mid \mathcal{I}_{x}\right]^{\frac{1}{\theta-1}}+\mathbb{E}\left[\left(\frac{\lambda\left(z_{x}, \mu_{x}, \hat{m}_{x}\right)}{(1+\tau) q}\right)^{\theta} \mid \mathcal{I}_{x}\right]^{\frac{1}{\theta-1}}\right]^{\frac{\theta-1}{\theta}}\right)^{\frac{\theta}{1-\theta}}}{\mathbb{E}\left[\lambda\left(z_{x}, \mu_{x}, \hat{m}_{y}\right)^{\theta} \mid \mathcal{I}_{x}\right]^{\frac{1}{\theta}}}\right) \\
& =z_{x}\left(\frac{Q\left(z_{x}, \mu_{x}, \hat{m}_{x} ; \frac{1}{q}, \frac{1}{1+\tau}\right)}{\bar{\lambda}\left(z_{x}, \mu_{x}, \hat{m}_{x}\right)}\right)^{\frac{\theta}{1-\theta}}
\end{aligned}
$$


Note that with perfect information: $Q\left(z_{x}, \mu_{x}, \hat{m}_{x} ; \frac{1}{q}, \frac{1}{1+\tau}\right)=\lambda\left(z_{x}, \mu_{x}, \hat{m}_{x}\right)\left(1+\left(\frac{1}{(1+\tau) q}\right)^{\frac{\theta}{\theta-1}}\right)^{\frac{\theta-1}{\theta}}$ and $\bar{\lambda}\left(z_{x}, \mu_{x}, \hat{m}_{x}\right)=$ $\lambda\left(z_{x}, \mu_{x}, \hat{m}_{x}\right)$, then the export expression simplifies to a linear function of $z_{x}$ :

$$
t_{x}=z_{x}\left(\frac{1}{1+((1+\tau) q)^{\frac{\theta}{1-\theta}}}\right)
$$

Analogously, one can show that firm optimal exports in the foreign country are given by:

$$
t_{y}\left(z_{y}, \mu_{y}, \hat{m}_{x}\right)=z_{y}\left(\frac{Q\left(z_{y}, \mu_{y}, \hat{m}_{x} ; q, \frac{1}{1+\tau}\right)}{\bar{\lambda}\left(z_{y}, \mu_{y}, \hat{m}_{x}\right)}\right)^{\frac{\theta}{1-\theta}}
$$

and with perfect information they reduce to:

$$
t_{y}=z_{y}\left(\frac{1}{1+\left(\frac{1+\tau}{q}\right)^{\frac{\theta}{1-\theta}}}\right)
$$

\section{A.2 Lemma 1: Exports are proportional to firm productivity}

Proof. Guess a solution $t(z, \mu, \hat{m})=z \Psi(\mu, \hat{m})$. First we show that the composite good is also proportional to $z$ :

$$
\begin{aligned}
c(z, \mu, \hat{m}) & \left.=\left((z-t(z, \mu, \hat{m}))^{\theta}+(t(z, \mu, \hat{m}) s p)\right)^{\theta}\right)^{1 / \theta} \\
& =\left(z^{\theta}(1-\Psi(\mu, \hat{m}))^{\theta}+z^{\theta}(\Psi(\mu, \hat{m}) s p)^{\theta}\right)^{1 / \theta} \\
& =z\left((1-\Psi(\mu, \hat{m}))^{\theta}+(\Psi(\mu, \hat{m}) s p)^{\theta}\right)^{1 / \theta} \\
& =z \Psi_{2}(\mu, \hat{m})
\end{aligned}
$$

where $\Psi_{2} \equiv\left((1-\Psi)^{\theta}+(\Psi s p)^{\theta}\right)^{1 / \theta}$.

Second, we substitute the composite consumption in $\bar{\lambda}$ and we obtain a separable function between idiosyncratic and aggregate variables:

$$
\begin{aligned}
\bar{\lambda}(z, \mu, \hat{m}) & \equiv \mathbb{E}\left[\lambda(z, \mu, \hat{m})^{\theta} \mid \mathcal{I}\right]^{\frac{1}{\theta}} \\
& =\mathbb{E}\left[c(z, \mu, \hat{m})^{1-\theta} \mid \mathcal{I}\right]^{\frac{1}{\theta}} \\
& =\mathbb{E}\left[z^{1-\theta} \Psi_{2}(\mu, \hat{m})^{1-\theta} \mid \mathcal{I}\right]^{\frac{1}{\theta}} \\
& =z^{\frac{1-\theta}{\theta}} \mathbb{E}\left[\Psi_{2}(\mu, \hat{m})^{1-\theta} \mid \mathcal{I}\right]^{\frac{1}{\theta}}
\end{aligned}
$$


Third, substitute $\lambda$ in $Q$ and again we obtain a separable function:

$$
\begin{aligned}
Q(z, \mu, \hat{m} ; p, s) & \equiv\left[\mathbb{E}\left[\lambda(z, \mu, \hat{m})^{\theta} \mid \mathcal{I}\right]^{\frac{1}{\theta-1}}+\mathbb{E}\left[(\lambda(z, \mu, \hat{m}) s p)^{\theta} \mid \mathcal{I}\right]^{\frac{1}{\theta-1}}\right]^{\frac{\theta-1}{\theta}} \\
& =\left[\mathbb{E}\left[c(z, \mu, \hat{m})^{1-\theta} \mid \mathcal{I}\right]^{\frac{1}{\theta-1}}+\mathbb{E}\left[c(z, \mu, \hat{m})^{1-\theta}(s p)^{\theta} \mid \mathcal{I}\right]^{\frac{1}{\theta-1}}\right]^{\frac{\theta-1}{\theta}} \\
& =\left[\mathbb{E}\left[z^{1-\theta} \Psi_{2}(\mu, \hat{m})^{1-\theta} \mid \mathcal{I}\right]^{\frac{1}{\theta-1}}+\mathbb{E}\left[z^{1-\theta} \Psi_{2}(\mu, \hat{m})^{1-\theta}(s p)^{\theta} \mid \mathcal{I}\right]^{\frac{1}{\theta-1}}\right]^{\frac{\theta-1}{\theta}} \\
& =\left[z^{-1} \mathbb{E}\left[\Psi_{2}(\mu, \hat{m})^{1-\theta} \mid \mathcal{I}\right]^{\frac{1}{\theta-1}}+z^{-1} \mathbb{E}\left[\Psi_{2}(\mu, \hat{m})^{1-\theta}(s p)^{\theta} \mid \mathcal{I}\right]^{\frac{1}{\theta-1}}\right]^{\frac{\theta-1}{\theta}} \\
& =z^{\frac{1-\theta}{\theta}}\left[\mathbb{E}\left[\Psi_{2}(\mu, \hat{m})^{1-\theta} \mid \mathcal{I}\right]^{\frac{1}{\theta-1}}+\mathbb{E}\left[\Psi_{2}(\mu, \hat{m})^{1-\theta}(s p)^{\theta} \mid \mathcal{I}\right]^{\frac{1}{\theta-1}}\right]^{\frac{\theta-1}{\theta}}
\end{aligned}
$$

Finally, substituting all the elements above in the implicit function that defines the export policy we get that terms with $z$ inside $Q$ and $\bar{\lambda}$ cancel out:

$$
\begin{aligned}
t(z, \mu, \hat{m}) & =z\left(\frac{Q(z, \mu, \hat{m} ; p, s)}{\bar{\lambda}(z, \mu, \hat{m})}\right)^{\frac{\theta}{1-\theta}} \\
& =z\left(\frac{\left.z^{\frac{1-\theta}{\theta}}\left[\mathbb{E}\left[\Psi_{2}(\mu, \hat{m})^{1-\theta} \mid \mathcal{I}\right]^{\frac{1}{\theta-1}}+\mathbb{E}\left[\Psi_{2}(\mu, \hat{m})^{1-\theta}(s p)^{\theta} \mid \mathcal{I}\right]^{\frac{1}{\theta-1}}\right]^{\frac{\theta-1}{\theta}}\right)^{\frac{\theta}{1-\theta}}}{z^{\frac{1-\theta}{\theta}} \mathbb{E}\left[\Psi_{2}(\mu, \hat{m})^{1-\theta} \mid \mathcal{I}\right]^{\frac{1}{\theta}}}\right) \\
& =z\left(\frac{\left.\left[\mathbb{E}\left[\Psi_{2}(\mu, \hat{m})^{1-\theta} \mid \mathcal{I}\right]^{\frac{1}{\theta-1}}+\mathbb{E}\left[\Psi_{2}(\mu, \hat{m})^{1-\theta}(s p)^{\theta} \mid \mathcal{I}\right]^{\frac{1}{\theta-1}}\right]^{\frac{\theta-1}{\theta}}\right)^{\frac{\theta}{1-\theta}}}{\mathbb{E}\left[\Psi_{2}(\mu, \hat{m})^{1-\theta} \mid \mathcal{I}\right]^{\frac{1}{\theta}}}\right. \\
& =z \Psi(\mu, \hat{m})
\end{aligned}
$$

Therefore, we have verified that the export policy is indeed linear in idiosyncratic productivity $z$.

Furthermore, the component that depends on aggregate shocks is given by:

$$
\Psi(\mu, \hat{m})=\left(\frac{\left[\mathbb{E}\left[\Psi_{2}(\mu, \hat{m})^{1-\theta} \mid \mathcal{I}\right]^{\frac{1}{\theta-1}}+\mathbb{E}\left[\Psi_{2}(\mu, \hat{m})^{1-\theta}(s p)^{\theta} \mid \mathcal{I}\right]^{\frac{1}{\theta-1}}\right]^{\frac{\theta-1}{\theta}}}{\mathbb{E}\left[\Psi_{2}(\mu, \hat{m})^{1-\theta} \mid \mathcal{I}\right]^{\frac{1}{\theta}}}\right)^{\frac{\theta}{1-\theta}}
$$

where

$$
\Psi_{2}(\mu, \hat{m})=\left((1-\Psi(\mu, \hat{m}))^{\theta}+(\Psi(\mu, \hat{m}) s p)^{\theta}\right)^{1 / \theta}
$$




\section{A.3 Derivation of fixed point problems}

Using Lemma 1, we can aggregate the exports of domestic and foreign firms:

$$
\begin{aligned}
& T_{x}\left(\mu_{x}, \hat{m}_{y}\right)=\int z_{x} \Psi\left(\mu_{x}, \hat{m}_{y}\right) d F\left(z_{x} \mid \mu_{x}\right)=e^{\mu_{x}+\frac{1}{2} \sigma_{x}^{2}} \Psi\left(\mu_{x}, \hat{m}_{y}\right) \\
& T_{y}\left(\mu_{y}, \hat{m}_{x}\right)=\int z_{y} \Gamma\left(\mu_{y}, \hat{m}_{x}\right) d F\left(z_{y} \mid \mu_{y}\right)=e^{\mu_{y}+\frac{1}{2} \sigma_{y}^{2}} \Gamma\left(\mu_{y}, \hat{m}_{x}\right)
\end{aligned}
$$

where the last equality holds because $z_{x}$ and $z_{y}$ are lognormal. Given the iceberg cost, only a fraction $\frac{1}{1+\tau}$ of exports arrive to the international markets. The actual equilibrium price will be given by:

$$
q\left(\mu_{x}, \mu_{y}, \hat{m}_{x}, \hat{m}_{y}\right)=\frac{T_{x}\left(\mu_{x}, \hat{m}_{y}\right) / 1+\tau}{T_{y}\left(\mu_{y}, \hat{m}_{x}\right) / 1+\tau}=\frac{e^{\mu_{x}+\frac{1}{2} \sigma_{x}^{2}} \Psi\left(\mu_{x}, \hat{m}_{y}\right)}{e^{\mu_{y}+\frac{1}{2} \sigma_{y}^{2}} \Gamma\left(\mu_{y}, \hat{m}_{x}\right)}=f \frac{\Psi\left(\mu_{x}, \hat{m}_{y}\right)}{\Gamma\left(\mu_{y}, \hat{m}_{x}\right)}
$$

where $f \equiv e^{\left(\mu_{x}-\mu_{y}\right)} e^{\frac{1}{2}\left(\sigma_{x}^{2}-\sigma_{y}^{2}\right)}$ are the relative fundamentals.

Rearranging $\Psi$ and $\Gamma$ and impose consistency of beliefs (the actual price function is used by agents to form their beliefs), we get that euilibrium is given by three functions $\Psi, \Gamma$ and $q$ such that they solve the following fixed point problems:

$$
\begin{aligned}
& \Psi\left(\mu_{x}, \hat{m}_{y}\right)=\frac{1}{1+(1+\tau)^{\frac{\theta}{1-\theta}}\left(\frac{\mathbb{E}_{\mu_{y}, \hat{m}_{x}}\left[\Psi_{2}\left(\mu_{x}, \mu_{y}, \hat{m}_{x}, \hat{m}_{y}\right)^{1-\theta} \mid \mathcal{I}_{x}\right]}{\mathbb{E}_{\mu_{y}, \hat{m}_{x}}\left[\Psi_{2}\left(\mu_{x}, \mu_{y}, \hat{m}_{x}, \hat{m}_{y}\right)^{1-\theta} q\left(\mu_{x}, \mu_{y}, \hat{m}_{x}, \hat{m}_{y}\right)^{-\theta} \mid \mathcal{I}_{x}\right]}\right)^{\frac{1}{1-\theta}}} \\
& \Gamma\left(\mu_{y}, \hat{m}_{x}\right)=\frac{1}{1+(1+\tau)^{\frac{\theta}{1-\theta}}\left(\frac{\mathbb{E}_{\mu_{x}, \hat{m}_{y}}\left[\Gamma_{2}\left(\mu_{y}, \mu_{x}, \hat{m}_{y}, \hat{m}_{x}\right)^{1-\theta} \mid \mathcal{I}_{y}\right]}{\mathbb{E}_{\mu_{x}, \hat{m}_{y}}\left[\Gamma_{2}\left(\mu_{y}, \mu_{x}, \hat{m}_{y}, \hat{m}_{x}\right)^{1-\theta} q\left(\mu_{x}, \mu_{y}, \hat{m}_{x}, \hat{m}_{y}\right)^{\theta} \mid \mathcal{I}_{y}\right]}\right)^{\frac{1}{1-\theta}}} \\
& q\left(\mu_{x}, \mu_{y}, \hat{m}_{x}, \hat{m}_{y}\right)=f \frac{\Psi\left(\mu_{x}, \hat{m}_{y}\right)}{\Gamma\left(\mu_{y}, \hat{m}_{x}\right)}
\end{aligned}
$$

where the auxiliary functions are:

$$
\begin{aligned}
& \Psi_{2}\left(\mu_{x}, \mu_{y}, \hat{m}_{x}, \hat{m}_{y}\right)=\left(\left(1-\Psi\left(\mu_{x}, \hat{m}_{y}\right)\right)^{\theta}+\left(\frac{\Psi\left(\mu_{x}, \hat{m}_{y}\right)}{(1+\tau) q\left(\mu_{x}, \mu_{y}, \hat{m}_{x}, \hat{m}_{y}\right)}\right)^{\theta}\right)^{1 / \theta} \\
& \Gamma_{2}\left(\mu_{y}, \mu_{x}, \hat{m}_{y}, \hat{m}_{x}\right)=\left(\left(1-\Gamma\left(\mu_{y}, \hat{m}_{x}\right)\right)^{\theta}+\left(\frac{\Gamma\left(\mu_{y}, \hat{m}_{x}\right) q\left(\mu_{y}, \mu_{x}, \hat{m}_{x}, \hat{m}_{y}\right)}{(1+\tau)}\right)^{\theta}\right)^{1 / \theta}
\end{aligned}
$$

This system can be expressed compactly as:

$$
\begin{aligned}
\Psi & =g_{1}\left(\mathcal{I}_{x}, \Psi, \Gamma\right) \\
\Gamma & =g_{2}\left(\mathcal{I}_{y}, \Psi, \Gamma\right) \\
q & =f g_{3}(\Psi, \Gamma)
\end{aligned}
$$




\section{B Algorithm}

\section{B.1 Polynomial approximation to policy functions}

Functional Basis Let $\left\{\Phi_{k}\right\}_{k=1}^{M}$ be a basis of polynomials with support $x \in[a, b]$. We use linear splines and uniform nodes for the 2 states of each country.

i) Grid for state 1: Own productivity:

- In $x$ country it is distributed $\mu_{x} \sim \mathcal{N}\left(m_{x}, s_{x}^{2}\right)$, where $m_{x}, s_{x}$ are parameters. We construct uniform nodes $\left\{\mu_{x}^{i}\right\}_{i=1}^{N}$ in the support $\left[m_{x}-4 s_{x}, m_{x}+4 s_{x}\right]$.

- In $y$ country it is distributed $\mu_{y} \sim \mathcal{N}\left(m_{y}, s_{y}^{2}\right)$, where $m_{y}, s_{y}$ are parameters. We construct uniform nodes $\left\{\mu_{y}^{i}\right\}_{i=1}^{N}$ in the support $\left[m_{y}-4 s_{y}, m_{y}+4 s_{y}\right]$.

ii) Grid for state 2: Posterior mean of foreign productivity:

- In $x$ country, the posterior mean of foreign productivity is $\hat{m}_{y} \sim \mathcal{N}\left(m_{y}, \bar{s}_{y}^{2}\right)$ where $\bar{s}_{y}^{2}=\frac{s_{y}^{4}}{s_{y}^{2}+\tilde{s}_{y}^{2}}$. However, to use a fixed grid that does not change with the precision of information, we construct the nodes $\left\{\hat{\mu}_{y}^{j}\right\}_{j=1}^{N}$ over the support $\left[m_{y}-4 s_{y}, m_{y}+4 s_{y}\right]$.

- In $y$ country, the posterior mean of foreign productivity is $\hat{m}_{x} \sim \mathcal{N}\left(m_{x}, \bar{s}_{x}^{2}\right)$ where $\bar{s}_{x}^{2}=\frac{s_{x}^{4}}{s_{x}^{2}+\tilde{s}_{x}^{2}}$. Analogously, we construct the nodes $\left\{\hat{m}_{x}^{j}\right\}_{j=1}^{N}$ over the support $\left[m_{x}-4 s_{x}, m_{x}+4 s_{x}\right]$.

Approximating functions We approximate four conditional expectations with polynomials:

$$
\begin{aligned}
\mathbb{E}_{\mu_{y}, \hat{m}_{x}}\left[\Psi_{2}\left(\mu_{x}, \hat{m}_{y}, \mu_{y}, \hat{m}_{x}\right)^{1-\theta} \mid \mathcal{I}_{x}\right] & \approx g^{1}\left(\mu_{x}, \hat{m}_{y}\right) \\
\mathbb{E}_{\mu_{y}, \hat{m}_{x}}\left[\Psi_{2}\left(\mu_{x}, \hat{m}_{y}, \mu_{y}, \hat{m}_{x}\right)^{1-\theta} q\left(\mu_{x}, \hat{m}_{y}, \mu_{y}, \hat{m}_{x}\right)^{-\theta} \mid \mathcal{I}_{x}\right] & \approx g^{2}\left(\mu_{x}, \hat{m}_{y}\right) \\
\mathbb{E}_{\mu_{x}, \hat{m}_{y}}\left[\Gamma_{2}\left(\mu_{y}, \hat{m}_{x}, \mu_{x}, \hat{m}_{y}\right)^{1-\theta} \mid \mathcal{I}_{y}\right] & \approx h^{1}\left(\mu_{y}, \hat{m}_{x}\right) \\
\mathbb{E}_{\mu_{x}, \hat{m}_{y}}\left[\Gamma_{2}\left(\mu_{y}, \hat{m}_{x}, \mu_{x}, \hat{m}_{y}\right)^{1-\theta} q\left(\mu_{x}, \hat{m}_{y}, \mu_{y}, \hat{m}_{x}\right)^{\theta} \mid \mathcal{I}_{y}\right] & \approx h^{2}\left(\mu_{y}, \hat{m}_{x}\right)
\end{aligned}
$$

where the polynomials are constructed using the basis for each dimension evaluated at the nodes described above:

$$
\begin{aligned}
g^{1}\left(\mu_{x}^{i}, \hat{m}_{y}^{j}\right) & \equiv \sum_{k, k^{\prime} \in K \times K^{\prime}} g_{k, k^{\prime}, i, j}^{1} \Phi_{k}\left(\mu_{x}^{i}\right) \Phi_{k^{\prime}}\left(\hat{m}_{y}^{j}\right) \\
g^{2}\left(\mu_{x}^{i}, \hat{m}_{y}^{j}\right) & \equiv \sum_{k, k^{\prime} \in K \times K^{\prime}} g_{k, k^{\prime}, i, j}^{2} \Phi_{k}\left(\mu_{x}^{i}\right) \Phi_{k^{\prime}}\left(\hat{m}_{y}^{j}\right) \\
h^{1}\left(\mu_{y}^{i}, \hat{m}_{x}^{j}\right) & \equiv \sum_{k, k^{\prime} \in K \times K^{\prime}} h_{k, k^{\prime}, i, j}^{1} \Phi_{k}\left(\mu_{y}^{i}\right) \Phi_{k^{\prime}}\left(\hat{m}_{x}^{j}\right), \\
h^{2}\left(\mu_{y}^{i}, \hat{m}_{x}^{j}\right) & \equiv \sum_{k, k^{\prime} \in K \times K^{\prime}} h_{k, k^{\prime}, i, j}^{2} \Phi_{k}\left(\mu_{y}^{i}\right) \Phi_{k^{\prime}}\left(\hat{m}_{x}^{j}\right)
\end{aligned}
$$

\section{B.2 Computing expectations}

For each country, we have two random variables, foreign productivity and second order beliefs, for which we will evaluate expectations using Gaussian Quadrature method. For this, we must define a set of nodes $\left\{x_{a}\right\}_{a=1}^{N_{q}}$ and weights $\left\{w_{a}\right\}_{a=1}^{N_{q}}$ such that

$$
\mathbb{E}[f(X)]=\sum_{a=1}^{N_{q}} w_{a} f\left(x_{a}\right)
$$

and further moments conditions are satisfied. 
- Grid for random variable 1: foreign productivity: The distribution of foreign aggregate productivity depends on the second state, the posterior mean $\hat{m}$.

- In $x$ country, for each value of the second state (the posterior mean) we have that foreign productivity is Normal with mean equal to the posterior mean $\hat{m}_{y}^{j}$ and variance equal to the posterior variance $\hat{s}_{y}^{2}=\left(s_{y}^{-2}+\tilde{s}_{y}^{-2}\right)^{-1}=$ $\frac{1}{\frac{1}{s_{y}^{2}}+\frac{1}{\tilde{s}_{y}^{2}}}$

$$
\mu_{y}^{j} \sim \mathcal{N}\left(\hat{m}_{y}^{j}, \hat{s}_{y}^{2}\right)
$$

Then for each $j=1, \ldots, N$, Gaussian Quadrature procedure constructs nodes of foreign productivity $\left\{\mu_{y}^{j, b}\right\}_{b}=$ $1, \ldots, N_{q}$ and corresponding weights $\left\{\omega^{b}\right\}_{b}=1, \ldots, N_{q}$. Note that the weights do not depend on $j$.

- In $y$ country, for each value of the second state (the posterior mean $\hat{m}_{x}^{j}$ ) we have that foreign productivity is Normal with mean equal to the posterior mean $\hat{m}_{x}^{j}$ and variance equal to the posterior variance $\hat{s}_{x}^{2}=$ $\left(s_{x}^{-2}+\tilde{s}_{x}^{-2}\right)^{-1}=\frac{1}{\frac{1}{s_{x}^{2}}+\frac{1}{\tilde{s}_{x}^{2}}}$

$$
\mu_{x}^{j} \sim \mathcal{N}\left(\hat{m}_{x}^{j}, \hat{s}_{x}^{2}\right)
$$

Then for each $j=1, \ldots, N$, Gaussian Quadrature procedure constructs nodes of foreign productivity $\left\{\mu_{x}^{j, b}\right\}_{b}=$ $1, \ldots, N_{q}$ and corresponding weights $\left\{\omega^{b}\right\}_{b}=1, \ldots, N_{q}$.

\section{Extreme cases}

- Perfect Info: As $\tilde{s}_{y} \rightarrow 0, \mu_{y}^{j} \sim \mathcal{N}\left(\hat{m}_{y}^{j}, 0\right)=\mathcal{N}\left(\mu_{y}^{j}, 0\right)$. The grid degenerates to a single point for each $j$ : $\mu_{y}^{j, b}=\mu_{y}^{j}$.

- No Info: As $\tilde{s}_{y} \rightarrow \infty, \mu_{y}^{j} \sim \mathcal{N}\left(\hat{m}_{y}^{j}, s_{y}^{2}\right)=\mathcal{N}\left(m_{y}, \bar{s}_{y}^{2}\right)$ which is equal the distribution of the posterior mean (the second state). Clearly, $\bar{s}_{y}^{2}=\frac{s_{y}^{4}}{s_{y}^{2}+\tilde{s}_{y}^{2}} \rightarrow s_{y}^{2}$ as well, which makes the distribution of foreign productivity equal to the prior. However, in the code we have fixed grids for the states so that they do not depend on signal precision. Therefore, as we reduce signal precision, the grid will not converge to the prior. However, the simulations take care of it.

- Grid for random variable 2: second order beliefs: From the perspective of the domestic country, the second order beliefs about the posterior mean (this is, what the domestic country thinks the posterior mean of the foreign country is) is a Normal random variable that depends on the first state, the domestic aggregate productivity $\mu$.

- In the $x$ country, for each value of the first state (aggregate productivity $\mu_{x}^{i}$ ), we have that the second order belief is Normal with mean and variance as follows:

$$
\hat{m}_{x}^{i} \sim \mathcal{N}\left(\hat{\hat{m}}_{x}^{i}, \hat{\hat{s}}_{x}^{2}\right) \quad \text { with } \quad \hat{\hat{m}}_{x}^{i} \equiv \frac{s_{x}^{-2} m_{x}+\tilde{s}_{p_{x}}^{-2} \mu_{x}^{i}}{s_{x}^{-2}+\tilde{s}_{p_{x}}^{-2}}, \quad \hat{\hat{s}}_{x}^{2} \equiv \tilde{s}_{p_{x}}^{-2}\left(s_{x}^{-2}+\tilde{s}_{p_{x}}^{-2}\right)^{-2}=\frac{1}{\left(\frac{\tilde{s}_{p_{x}}}{s_{x}^{2}}+\frac{1}{\tilde{s}_{p_{x}}}\right)^{2}}
$$

where $\tilde{s}_{p_{x}}$ is the foreign signal noise as perceived by the domestic country. With known information structures $\tilde{s}_{p_{x}}=\tilde{s}_{x}$, but with unknown information structures $\tilde{s}_{p_{x}} \neq \tilde{s}_{x}$.

Then for each $i=1, \ldots, N$, Gaussian Quadrature procedure constructs nodes for second order beliefs $\left\{\mu_{x}^{i, a}\right\}_{a}=$ $1, \ldots, N_{q}$ and corresponding weights $\left\{\gamma^{a}\right\}_{a}=1, \ldots, N_{q}$.

- In the $y$ country, we have that for each value of the first state $\mu_{y}^{i}$ the second order belief is distributed as:

$$
\hat{m}_{y}^{i} \sim \mathcal{N}\left(\hat{\hat{m}}_{y}^{i}, \hat{\hat{s}}_{y}^{2}\right) \quad \text { with } \quad \hat{\hat{m}}_{y}^{i} \equiv \frac{s_{y}^{-2} m_{y}+\tilde{s}_{p_{y}}^{-2} \mu_{y}^{i}}{s_{y}^{-2}+\tilde{s}_{p_{y}}^{-2}}, \quad \hat{\hat{s}}_{y}^{2} \equiv \tilde{s}_{p_{y}}^{-2}\left(s_{y}^{-2}+\tilde{s}_{p_{y}}^{-2}\right)^{-2}=\frac{1}{\left(\frac{\tilde{s}_{p_{y}}}{s_{y}^{2}}+\frac{1}{\tilde{s}_{p_{y}}}\right)^{2}}
$$




\section{Extreme cases}

- Perfect Info: As $\tilde{s}_{p_{x}} \rightarrow 0$, then the distribution becomes degenerate at the true realizations: $\hat{m}_{x}^{i} \sim$ $\mathcal{N}\left(\mu_{x}^{i}, 0\right) \quad \forall i$ and the grid becomes: $\hat{m}_{x}^{i, a}=\mu_{x}^{i}, a=1, \ldots, N_{q}$

- Imperfect Info: As $\tilde{s}_{p_{x}} \rightarrow \infty$, then the distribution becomes degenerate at the prior means $\hat{m}_{x}^{i} \sim$ $\mathcal{N}\left(m_{x}, 0\right) \quad \forall i$ and the grid becomes $\hat{m}_{x}^{i, a}=m_{x}, a=1, \ldots, N$

\section{B.3 Finding the fixed point}

1. For reference, we organize the states as follows. For $\mathrm{x}$ - country: $\left(\mu_{x}, \hat{m}_{y}\right)$ and for y - country: $\left(\mu_{y}, \hat{m}_{x}\right)$. For the price and other economy wide variables, we make the following convention: $q\left(\mu_{x}, \hat{m}_{y}, \mu_{y}, \hat{m}_{x}\right)$.

2. Guess initial set of coefficients for polynomials $\left\{g_{k, k^{\prime}, i, j}^{1}, g_{k, k^{\prime}, i, j}^{2}, h_{k, k^{\prime}, i, j}^{1}, h_{k, k^{\prime}, i, j}^{2}\right\}$.

- We start by solving the perfect information case and approximate the policies with the polynomials to get the first set of coefficients. Since with perfect information $\hat{m}_{y}=\mu_{y}$ and $\hat{m}_{x}=\mu_{x}$, we have the following system of equations:

$$
\begin{aligned}
\Psi^{P I}\left(\mu_{x}, \mu_{y}\right) & =\frac{1}{1+\left[(1+\tau) q^{P I}\left(\mu_{x}, \mu_{y}\right)\right]^{\frac{\theta}{1-\theta}}} \\
\Gamma^{P I}\left(\mu_{y}, \mu_{x}\right) & =\frac{1}{1+\left[\frac{(1+\tau)}{q^{P I}\left(\mu_{x}, \mu_{y}\right)}\right]^{\frac{\theta}{1-\theta}}} \\
q^{P I}\left(\mu_{x}, \mu_{y}\right) & =f \frac{\Psi^{P I}\left(\mu_{x}, \mu_{y}\right)}{\Gamma\left(\mu_{y}, \mu_{x}\right)}
\end{aligned}
$$

Thus $q^{P I}$ solves the following equation ${ }^{2}$ :

$$
q^{P I}-f \frac{\frac{1}{1+\left[(1+\tau) q^{P I}\left(\mu_{x}, \mu_{y}\right)\right]^{\frac{\theta}{1-\theta}}}}{\frac{1}{1+\left[\frac{(1+\tau)}{q^{P I}\left(\mu_{x}, \mu_{y}\right)}\right]^{\frac{\theta}{1-\theta}}}}=0
$$

Once we have the price, we recover the policies and construct the first guess of coefficients and approximating functions.

3. For the $\mathrm{X}$ - country:

- For each state $\left(\mu_{x}^{i}, \hat{m}_{y}^{j}\right)$, approximate $\Psi$ using the polynomials $g^{1}$ and $g^{2}$ evaluated at the state:

$$
\Psi\left(\mu_{x}^{i}, \hat{m}_{y}^{j}\right) \approx \frac{1}{1+(1+\tau)^{\frac{\theta}{1-\theta}}\left(\frac{g^{1}\left(\mu_{x}^{i}, \hat{m}_{y}^{j}\right)}{g^{2}\left(\mu_{x}^{i}, \hat{m}_{y}^{j}\right)}\right)^{\frac{1}{1-\theta}}}
$$

- For each quadrature node $\left(\mu_{y}^{a}, \hat{m}_{x}^{b}\right)$ approximate $\Gamma$ using the polynomials $h^{1}$ and $h^{2}$ evaluate at the nodes $\left\{\mu_{y}^{a}\right\}_{a=1}^{N_{q}},\left\{\hat{m}_{x}^{b}\right\}_{b=1}^{N_{q}}$

$$
\Gamma\left(\mu_{y}^{a}, \hat{m}_{x}^{b}\right) \approx \frac{1}{1+(1+\tau)^{\frac{\theta}{1-\theta}}\left(\frac{h^{1}\left(\mu_{y}^{a}, \hat{m}_{x}^{b}\right)}{h^{2}\left(\mu_{y}^{a}, \hat{m}_{x}^{b}\right)}\right)^{\frac{1}{1-\theta}}}
$$

\footnotetext{
${ }^{2}$ Notice that without the trade cost $\tau$, the price is: $q^{P I}\left(\mu_{x}, \mu_{y}\right)=f^{1-\theta} \quad \forall\left(\mu_{y}, \mu_{x}\right)$.
} 
- Construct $q$ and $\Psi_{2}$ in 4 dimensions using $\Psi\left(\mu_{x}^{i}, \hat{m}_{y}^{j}\right)$ and $\Gamma\left(\mu_{y}^{a}, \hat{m}_{x}^{b}\right)$ :

$$
\begin{gathered}
q\left(\mu_{x}^{i}, \hat{m}_{y}^{j}, \mu_{y}^{a}, \hat{m}_{x}^{b}\right) \approx e^{\left(\mu_{x}^{i}-\mu_{y}^{a}\right)} e^{\frac{1}{2}\left(\sigma_{x}^{2}-\sigma_{y}^{2}\right)} \frac{\Psi\left(\mu_{x}^{i}, \hat{m}_{y}^{j}\right)}{\Gamma\left(\mu_{y}^{a}, \hat{m}_{x}^{b}\right)} \\
\Psi_{2}\left(\mu_{x}^{i}, \hat{m}_{y}^{j}, \mu_{y}^{a}, \hat{m}_{x}^{b}\right)=\left(\left(1-\Psi\left(\mu_{x}^{i}, \hat{m}_{y}^{j}\right)\right)^{\theta}+\left(\frac{\Psi\left(\mu_{x}^{i}, \hat{m}_{y}^{j}\right)}{(1+\tau) q\left(\mu_{x}^{i}, \hat{m}_{y}^{j}, \mu_{y}^{a}, \hat{m}_{x}^{b}\right)}\right)^{\theta}\right)^{\frac{1}{\theta}}
\end{gathered}
$$

- Compute the conditional expectations of $\Psi_{2}^{1-\theta}$ and $\Psi_{2}^{1-\theta} q^{-\theta}$ that integrate out the two random variables $\left(\mu_{y}, \hat{m}_{x}\right)$ as the weighted sum of the functions evaluated at the quadrature nodes, using the quadrature weights $\left\{\omega^{a}\right\}_{a=1}^{N_{q}}$ and $\left\{\gamma^{b}\right\}_{b=1}^{N_{q}}$ :

$$
\begin{gathered}
\mathbb{E}_{\mu_{y}, \hat{m}_{x}}\left[\Psi_{2}^{1-\theta}\left(\mu_{x}, \hat{m}_{y}, \mu_{y}, \hat{m}_{x}\right) \mid \mathcal{I}_{x}\right] \\
=\int_{\mu_{y}} \int_{\hat{m}_{x}} \Psi_{2}^{1-\theta}\left(\mu_{x}, \hat{m}_{y}, \mu_{y}, \hat{m}_{x}\right) \phi\left(\frac{\mu_{y}-\hat{m}_{y}}{\hat{s}_{y}}\right) \phi\left(\frac{\hat{m}_{x}-\hat{\hat{m}}_{x}}{\hat{\hat{s}}_{x}}\right) d \mu_{y} d \hat{m}_{x} \\
\approx \sum_{a=1}^{N_{q}} \sum_{b=1}^{N_{q}} \omega^{a} \gamma^{b} \Psi_{2}^{1-\theta}\left(\mu_{x}^{i}, \hat{m}_{y}^{j}, \mu_{y}^{a}, \hat{m}_{x}^{b}\right) \\
\mathbb{E}_{\mu_{y}, \hat{m}_{x}}\left[\Psi_{2}^{1-\theta}\left(\mu_{x}, \hat{m}_{y}, \mu_{y}, \hat{m}_{x}\right) q^{-\theta}\left(\mu_{x}, \hat{m}_{y}, \mu_{y}, \hat{m}_{x}\right) \mid \mathcal{I}_{x}\right] \\
=\int_{\mu_{y}} \int_{\hat{m}_{x}} \Psi_{2}^{1-\theta}\left(\mu_{x}, \hat{m}_{y}, \mu_{y}, \hat{m}_{x}\right) q^{-\theta}\left(\mu_{x}, \hat{m}_{y}, \mu_{y}, \hat{m}_{x}\right) \phi\left(\frac{\mu_{y}-\hat{m}_{y}}{\hat{s}_{y}}\right) \phi\left(\frac{\hat{m}_{x}-\hat{\hat{m}}_{x}}{\hat{\hat{s}}_{x}}\right) d \mu_{y} d \hat{m}_{x} \\
\approx \sum_{a=1}^{N_{q}} \sum_{b=1}^{N_{q}} \omega^{a} \gamma^{b} \Psi_{2}^{1-\theta}\left(\mu_{x}^{i}, \hat{m}_{y}^{j}, \mu_{y}^{a}, \hat{m}_{x}^{b}\right) q^{-\theta}\left(\mu_{x}^{i}, \hat{m}_{y}^{j}, \mu_{y}^{a}, \hat{m}_{x}^{b}\right)
\end{gathered}
$$

4. For the Y- country, we do analogous calculations.

- For each state $\left(\mu_{y}^{i}, \hat{m}_{x}^{j}\right)$, approximate $\Gamma$ using the polynomials $h^{1}$ and $h^{2}$ evaluated at the state:

$$
\Gamma\left(\mu_{y}^{i}, \hat{m}_{x}^{j}\right) \approx \frac{1}{1+(1+\tau)^{\frac{\theta}{1-\theta}}\left(\frac{h^{1}\left(\mu_{y}^{i}, \hat{m}_{x}^{j}\right)}{h^{2}\left(\mu_{y}^{i}, \hat{m}_{x}^{j}\right)}\right)^{\frac{1}{1-\theta}}}
$$

- For each quadrature node $\left(\mu_{x}^{a}, \hat{m}_{y}^{b}\right)$ approximate $\Psi$ using the polynomials $g^{1}$ and $g^{2}$ evaluate at the nodes $\left\{\mu_{x}^{a}\right\}_{a=1}^{N_{q}},\left\{\hat{m}_{y}^{b}\right\}_{b=1}^{N_{q}}$

$$
\Psi\left(\mu_{x}^{a}, \hat{m}_{y}^{b}\right) \approx \frac{1}{1+(1+\tau)^{\frac{\theta}{1-\theta}}\left(\frac{g^{1}\left(\mu_{x}^{a}, \hat{m}_{y}^{b}\right)}{g^{2}\left(\mu_{x}^{a}, \hat{m}_{y}^{b}\right)}\right)^{\frac{1}{1-\theta}}}
$$

- Construct $q$ and $\Gamma_{2}$ in 4 dimensions using $\Gamma\left(\mu_{y}^{i}, \hat{m}_{x}^{j}\right)$ and $\Psi\left(\mu_{x}^{a}, \hat{m}_{y}^{b}\right)$ (note that the state for the price is in the same order as for the X-country):

$$
\begin{gathered}
q\left(\mu_{x}^{a}, \hat{m}_{y}^{b}, \mu_{y}^{i}, \hat{m}_{x}^{j}\right) \approx e^{\left(\mu_{x}^{a}-\mu_{y}^{i}\right)} e^{\frac{1}{2}\left(\sigma_{x}^{2}-\sigma_{y}^{2}\right)} \frac{\Psi\left(\mu_{x}^{a}, \hat{m}_{y}^{b}\right)}{\Gamma\left(\mu_{y}^{i}, \hat{m}_{x}^{j}\right)} \\
\Gamma_{2}\left(\mu_{y}^{i}, \hat{m}_{x}^{j}, \mu_{x}^{a}, \hat{m}_{y}^{b}\right)=\left(\left(1-\Gamma\left(\mu_{y}^{i}, \hat{m}_{x}^{j}\right)\right)^{\theta}+\left(\frac{\Gamma\left(\mu_{y}^{i}, \hat{m}_{x}^{j}\right) q\left(\mu_{x}^{a}, \hat{m}_{y}^{b}, \mu_{y}^{i}, \hat{m}_{x}^{j}\right)}{(1+\tau)}\right)^{\theta}\right)^{\frac{1}{\theta}}
\end{gathered}
$$


- Compute the conditional expectations of $\Gamma_{2}^{1-\theta}$ and $\Gamma_{2}^{1-\theta} q^{\theta}$ that integrate out the two random variables $\left(\mu_{x}, \hat{m}_{y}\right)$. This is just the weighted sum of the functions evaluated at the quadrature nodes, using the quadrature weights $\left\{\omega^{a}\right\}_{a=1}^{N_{q}}$ and $\left\{\gamma^{b}\right\}_{b=1}^{N_{q}}$ :

$$
\begin{gathered}
\mathbb{E}_{\mu_{x}, \hat{m}_{y}}\left[\Gamma_{2}^{1-\theta}\left(\mu_{y}, \hat{m}_{x}, \mu_{x}, \hat{m}_{y}\right) \mid \mathcal{I}_{y}\right] \\
=\int_{\mu_{y}} \int_{\hat{m}_{x}} \Gamma_{2}^{1-\theta}\left(\mu_{y}, \hat{m}_{x}, \mu_{x}, \hat{m}_{y}\right) \phi\left(\frac{\mu_{x}-\hat{m}_{x}}{\hat{s}_{x}}\right) \phi\left(\frac{\hat{m}_{y}-\hat{\hat{m}}_{y}}{\hat{\hat{s}}_{y}}\right) d \mu_{x} d \hat{m}_{y} \\
\approx \sum_{a=1}^{N_{q}} \sum_{b=1}^{N_{q}} \omega^{a} \gamma^{b} \Gamma_{2}^{1-\theta}\left(\mu_{y}^{i}, \hat{m}_{x}^{j}, \mu_{x}^{a}, \hat{m}_{y}^{b}\right) \\
\mathbb{E}_{\mu_{x}, \hat{m}_{y}}\left[\Gamma_{2}^{1-\theta}\left(\mu_{y}, \hat{m}_{x}, \mu_{x}, \hat{m}_{y}\right) q^{\theta}\left(\mu_{x}, \hat{m}_{y}, \mu_{y}, \hat{m}_{x}\right) \mid \mathcal{I}_{y}\right] \\
=\int_{\mu_{y}} \int_{\hat{m}_{x}} \Gamma_{2}^{1-\theta}\left(\mu_{y}, \hat{m}_{x}, \mu_{x}, \hat{m}_{y}\right) q^{\theta}\left(\mu_{x}, \hat{m}_{y}, \mu_{y}, \hat{m}_{x}\right) \phi\left(\frac{\mu_{x}-\hat{m}_{x}}{\hat{s}_{x}}\right) \phi\left(\frac{\hat{m}_{y}-\hat{\hat{m}}_{y}}{\hat{\hat{s}}_{y}}\right) d \mu_{x} d \hat{m}_{y} \\
\approx \sum_{a=1}^{N_{q}} \sum_{b=1}^{N_{q}} \omega^{a} \gamma^{b} \Gamma_{2}^{1-\theta}\left(\mu_{x}^{i}, \hat{m}_{y}^{j}, \mu_{y}^{a}, \hat{m}_{x}^{b}\right) q^{\theta}\left(\mu_{x}^{a}, \hat{m}_{y}^{b}, \mu_{y}^{i}, \hat{m}_{x}^{j}\right)
\end{gathered}
$$

5. Update coefficients by i) fitting polynomials to approximate the conditional expectations and ii) using a linear combination of the new coefficients with the previous guess.

6. Repeat steps until convergence of coefficients.

7. Once convergence is achieved, recover all variables at the firm level and at the aggregate level.

Recall the definitions of domestic, foreign and relative fundamentals:

$$
f_{x} \equiv e^{\mu_{x}+\frac{1}{2} \sigma_{x}^{2}}, \quad f_{y} \equiv e^{\mu_{y}+\frac{1}{2} \sigma_{y}^{2}} \quad f \equiv e^{\left(\mu_{x}-\mu_{y}\right)} e^{\frac{1}{2}\left(\sigma_{x}^{2}-\sigma_{y}^{2}\right)}
$$

(a) Price function:

$$
q\left(\mu_{x}, \mu_{y}, \hat{m}_{x}, \hat{m}_{y}\right)=f \frac{\Psi\left(\mu_{x}, \hat{m}_{y}\right)}{\Gamma\left(\mu_{y}, \hat{m}_{x}\right)}
$$

(b) Firms' export policy and consumptions in $x$ country:

$$
\begin{aligned}
t_{x}\left(z_{x}, \mu_{x}, \hat{m}_{y}\right) & =z_{x} \Psi\left(\mu_{x}, \hat{m}_{y}\right) \\
c_{x}\left(z_{x}, \mu_{x}, \hat{m}_{y}\right) & =z_{x}\left(1-\Psi\left(\mu_{x}, \hat{m}_{y}\right)\right) \\
c_{y}\left(z_{x}, \mu_{x}, \hat{m}_{y}, \mu_{y}, \hat{m}_{x}\right) & =\frac{t_{x}\left(z_{x}, \mu_{x}, \hat{m}_{y}\right)}{(1+\tau) q\left(\mu_{x}, \mu_{y}, \hat{m}_{x}, \hat{m}_{y}\right)} \\
c\left(z_{x}, \mu_{x}, \hat{m}_{y}, \mu_{y}, \hat{m}_{x}\right) & =z_{x} \Psi_{2}\left(\mu_{x}, \hat{m}_{y}, \mu_{y}, \hat{m}_{x}\right)
\end{aligned}
$$

(c) Firms' export policy and consumptions in $y$ country:

$$
\begin{aligned}
t_{y}\left(z_{y}, \mu_{y}, \hat{m}_{x}\right) & =z_{y} \Gamma\left(\mu_{y}, \hat{m}_{x}\right) \\
c_{y}^{*}\left(z_{y}, \mu_{y}, \hat{m}_{x}\right) & =z_{y}\left(1-\Gamma\left(\mu_{y}, \hat{m}_{x}\right)\right) \\
c_{x}^{*}\left(z_{y}, \mu_{y}, \hat{m}_{x}, \mu_{x}, \hat{m}_{y}\right) & =\frac{t_{y}\left(z_{y}, \mu_{y}, \hat{m}_{x}\right) q\left(\mu_{x}, \mu_{y}, \hat{m}_{x}, \hat{m}_{y}\right)}{(1+\tau)} \\
c^{*}\left(z_{x}, \mu_{x}, \hat{m}_{y}, \mu_{y}, \hat{m}_{x}\right) & =z_{y} \Gamma_{2}\left(\mu_{y}, \hat{m}_{x}, \mu_{x}, \hat{m}_{y}\right)
\end{aligned}
$$


(d) Aggregate variables in $x$ country:

$$
\begin{aligned}
T_{x}\left(\mu_{x}, \hat{m}_{y}\right) & =f_{x} \Psi\left(\mu_{x}, \hat{m}_{y}\right) \\
C_{x}\left(\mu_{x}, \hat{m}_{y}\right) & =f_{x}\left(1-\Psi\left(\mu_{x}, \hat{m}_{y}\right)\right) \\
C_{y}\left(\mu_{x}, \hat{m}_{y}, \mu_{y}, \hat{m}_{x}\right) & =\frac{T_{x}\left(\mu_{x}, \hat{m}_{y}\right)}{(1+\tau) q\left(\mu_{x}, \mu_{y}, \hat{m}_{x}, \hat{m}_{y}\right)} \\
C\left(\mu_{x}, \hat{m}_{y}, \mu_{y}, \hat{m}_{x}\right) & =f_{x} \Psi_{2}\left(\mu_{x}, \mu_{y}, \hat{m}_{x}, \hat{m}_{y}\right)
\end{aligned}
$$

(e) Aggregate variables in $y$ country:

$$
\begin{aligned}
T_{y}\left(\mu_{y}, \hat{m}_{x}\right) & =f_{y} \Gamma\left(\mu_{y}, \hat{m}_{x}\right) \\
C_{y}^{*}\left(\mu_{y}, \hat{m}_{x}\right) & =f_{y}\left(1-\Gamma\left(\mu_{y}, \hat{m}_{x}\right)\right) \\
C_{x}^{*}\left(\mu_{y}, \hat{m}_{x}, \mu_{x}, \hat{m}_{y}\right) & =\frac{T_{y}\left(\mu_{y}, \hat{m}_{x}\right) q\left(\mu_{x}, \mu_{y}, \hat{m}_{x}, \hat{m}_{y}\right)}{(1+\tau)} \\
C^{*}\left(\mu_{y}, \hat{m}_{x}, \mu_{x}, \hat{m}_{y}\right) & =f_{y} \Gamma_{2}\left(\mu_{y}, \hat{m}_{x}, \mu_{x}, \hat{m}_{y}\right)
\end{aligned}
$$

